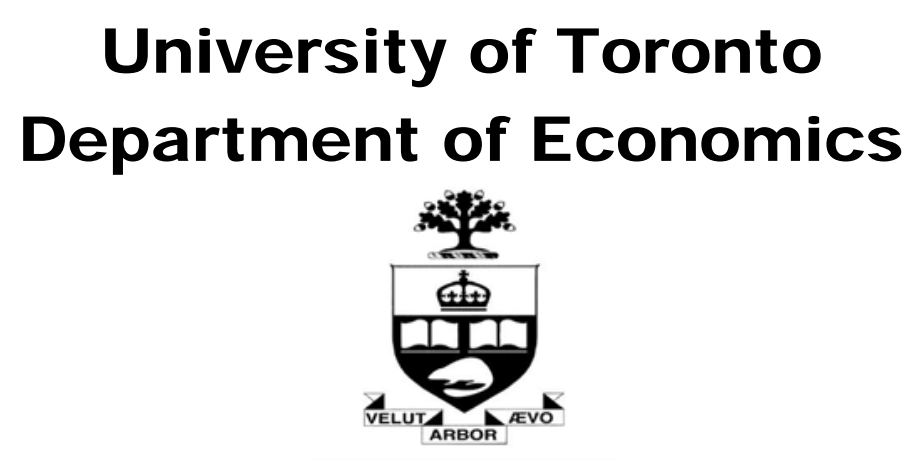

Working Paper 325

Network Structure and Design in the Deregulated U.S. Airline Industry: an Argument for Re-Regulation?

By Sayed Ajaz Hussain and Serkan Bahceci

August 08, 2008 


\title{
Network Structure and Design in the Deregulated U.S. Airline Industry: an Argument for Re-Regulation?
}

\author{
Sayed Ajaz Hussain* $\quad$ Serkan Bahçeci ${ }^{\dagger}$
}

\begin{abstract}
This paper develops a model to explain and analyze the evolution of network structure (connectivity) and design (flight frequency, aircraft size, prices) in the post-deregulation U.S. airline industry. We show that legacy carriers choice of Hub-and-Spoke networks and the emergence of low cost carriers (LCCs) operating Point-to-Point networks were optimal choices. We demonstrate that LCCs need not necessarily charge lower prices, and their entry impacted legacy carriers' prices in all markets, even those where there is no direct competition. We show that in response to entry, legacy carriers optimally lower flight frequency, leading to longer wait times between flights for which passengers are compensated by lower prices; conversely, if the entrant later exits, legacy carriers raise flight frequency and therefore prices, which may erroneously appear to be predatory pricing when in fact it is the consequence of optimal network redesign. Finally, we demonstrate that even though low cost carriers lower prices, total social welfare with competing network structures can also be lowered. In other words, the poor financial performance of legacy carriers is not due to their inefficiency per se but due to an efficient Hub-and-Spoke network undermined by competition from inefficient Point-to-Point networks. We argue that social welfare may have been, and still can be, higher if entry and exit in air passenger travel industry is regulated.
\end{abstract}

\section{Introduction}

Seventy years ago, in an effort to protect airlines from the 'deleterious effects of excessive competition', Congress passed the Civil Aviation Act to regulate the industry. ${ }^{1}$ The regulatory body, the Civil Aviation Board (CAB), grandfathered all trunk (medium and long distance) routes and for the next forty years, regulated fares, entry/exit, route structure and the degree of rivalry over trunk routes. $^{2}$. By 1978, the combination of high oil prices, popular and political dissatisfaction with regulation and the emergence of the contestable markets theory led to deregulation of the industry.

On the 30th anniversary of deregulation, we ask- like many others- whether deregulation has been 'successful'? For many, the proof is in the pudding: the current juxtaposition of legacy carriers- plagued with chronic losses, saddled with high costs, and shrinking market shares- and the so called low cost carriers (LCCs)- blessed with profits year after year, low costs and ever

\footnotetext{
${ }^{*}$ Department of Economics University of Toronto. Email: sayed.hussainutoronto.ca. We thank: Shoaib Zaidi, Ivor Morgan, the late Hsiang-Ling Han, Kyung-won Min and Amar Sahay for research assistance with the empirics. The usual disclaimers apply.

$\dagger$ JPMorgan Asset Management. The views expressed in this paper are the views of the authors and do not necessarily reflect the views or policies of JPMorgan Asset Management (JPMAM). JPMAM does not guarantee the accuracy of the data included in this paper and accepts no responsibility for it use. The Matlab code for the model is available at http://www.economics.utoronto.ca/ahussain/papers/hussainbahceci.m

${ }^{1}$ For excellent overviews and analyses see: Meyer et al (1981), McCraw (1984), Borenstein (1992), McGahan (1995), Morrison and Winston (1995), Brueckner et al (1997), Doganis (1993), Lee (2006).

${ }^{2}$ The CAB allowed entry into 'local' (short distance) routes.
} 
expanding market shares. Not surprisingly, the popular press and the business literature tout the "LCC business model" as the future of air travel. According to these, legacy carriers will ultimately exit the industry, to be replaced by LCCs which will bring consumers lower prices and direct connections. It has been argued, that competition by LCCs has had a salubrious impact on social welfare.

While these claims may be valid, we argue that a closer look at the evolution of the U.S. airline industry since 1978 and the LCC business model raises more questions than answers about whether deregulation was "successful". In the years after deregulation in 1978, new carriers poured in, driving down prices and concentration levels. By the mid-80s, many of these new carriers exited, raising concentration levels ${ }^{3}$ and prices, leading some to wonder whether deregulation had been a failure. This prompted a closer scrutiny of legacy carriers' dominance.

One explanation was that legacy carriers' computer reservation systems, frequent flyer mile programs and larger networks were endogenous barriers to entry (McGahan (1995), Banerjee and Summers (1987)). Another explanation focused on the validity of applying contestable market theory to airlines - 'marginal costs with wings' (Alfred Kahn, CAB chief, in McCraw (1984)). But perhaps the most influential explanation was based on the stylistic fact that following deregulation, legacy carriers- now able to enter and exit any route- formed Hub-and-Spoke (HS) networks. In turn, this spawned investigations of why legacy carriers formed HS networks.

Explanations abound for the emergence of HS networks. One is that the hub-dominant carrier has market power on 'spoke' routes to/from the hub, which allows it to charge "hub premiums'. Studies by the U.S. General Accounting Office (1990, 1999), U.S. Department of Transportation (1990, 2001), Borenstein (1989), and Evans and Kessides (1993) provide evidence of these hub premiums. The counter-argument is that the hub premiums may be due to omitted variables such as higher flight frequencies at hubs or a greater proportion of business passengers who are willing to pay higher prices traveling to/through/from hubs (Lee and Luengo-Prado (2005); Berry, Carnall, Spiller (2006)) or that hub airports have barriers to entry (Abramowitz and Brown (1990) $)^{4}$.

A second argument is that HS networks may offer strategic advantages in accommodating/deterring entrants $^{5}$. A third argument is that under general demand and cost assumptions, HS networks are more efficient than, say, Point-to-Point (P2P) networks due to economies of density and scale. For example: if demand between Origin-Destination (O-D) city pairs is low relative to aircraft size, it is cheaper to take passengers from all origin cities- irrespective of their destination- to a hub, where they- irrespective of their origins- they are placed on flights to destination cities. Such a routing allows for greater aircraft utilization compared to if carriers operated direct flights ${ }^{6}$. The efficiency of HS networks is underscored by its prevalence in a range of transport systems ranging from trains and mail to power and overnight packages. Economists have long recognized the 'efficiency' of HS networks, to the extent that currently, papers are still being written about why these networks emerged after deregulation.

However, the almost singular focus on HS networks in the economics literature runs into a problematic counter-fact: the recent emergence of carriers operating Point-to-Point (P2P) networks. These P2P carriers such Southwest and Jet Blue are apparently also "low cost carriers (LCCs)", which as Borenstein (1992) noted, presents a paradox for airline economics:

The cost heterogeneity [between legacy and low cost carriers] appears to be as significant

\footnotetext{
${ }^{3}$ For example, by $198892 \%$ of the industry was served by eight carriers with the 'big three'- American, Delta and United- holding 50\% of the market (McGahan (1995). See also Borenstein (1992).

${ }^{4}$ In this paper, we contribute to this debate by identifying two omitted variables: network structure and whether travel is between major or secondary airports.

${ }^{5}$ Hendricks, Piccione and Tan (1997), Oum, Zhang, and Zhang (1995), Shy (2001). Aguirregabiria and Ho (2007) estimate a dynamic oligopoly model in which passengers benefit from the scale of a hub and where HS networks deters entrants.

${ }^{6}$ See (Berechman and Shy $(1996,1998)$, Bittlingmayer (1990), Caves, Christensen and Tretheway (1984), Brueckner and Spiller (1997).
} 
as ever, with the highest cost airline, US Air, exhibiting unit costs about 64 percent above Southwest's. Caves, Christensen, and Tretheway [1984] identify average flight length as the most significant cause of costs heterogeneity, but Southwest actually has a shorter average flight length than US Air, implying that Southwest should exhibit higher costs. America West, which operates a more traditional hub-and-spoke system than Southwest .. has much lower costs than the other major airlines while flying shorter average trips than most of the others. What is the source of these cost differences?

Borenstein (1992) argued that Southwest's cost advantage stems from better management. ${ }^{7}$ In addition to better management, the business literature and Wall Street attributes LCC's lower cost to their business model: a P2P network and a fleet consisting of homogeneous aircraft types, where the latter is credited for economies of scale in purchasing, maintenance and operations ${ }^{8}$. The lower fares ushered by the success of LCCs- operating P2P networks with a homogeneous fleetjuxtaposed with the increasingly weak performance of legacy carriers- operating HS networks with heterogeneous fleet- has led some economic pundits to applaud LCCs as proof that competition is (finally) working and led to management gurus touting P2P networks as the future of air travel. This paper examines these claims: are LCCs really low cost carriers? Do LCCs really charge lower fares? Is deregulation (finally) a success due to low fare, low cost carriers? Answers to these questions require a model of endogenous network structure - connectivity - and design- frequencies, aircraft sizes, prices- which explains why legacy carriers chose HS networks, why LCCs chose (apparently inefficient) P2P networks, and the source of LCC's low fares, and an analysis of social welfare.

The starting point of our analysis is to note that intuitively with high demand, short routelength, small aircrafts, high passenger premium for frequent flights and direct connections, low flight operational costs, a P2P network may be superior to a HS network. Clearly, a complete investigation requires a model of endogenous network structure- connectivity - and network designflight frequency, aircraft size, prices. While there are a number of papers in economics on network structure and design- Hendricks, Piccione, Tan (1995, 1999); Oum, Zhang, Zhang (1995); Starr and Stinchcombe (1992), Berechman and Shy (1996), Hendricks, Piccione, Tan (1995, 1999), Barla (1999), Schipper and Nijkamp (1998), Adler (2005), and, Daniel and Pahwa (2007)- none truly endogenize structure and design. For our purposes, the best suited model is Lederer and Nambimadom (1998)- hereafter LN- from the operations research literature. Their model encompasses various factors that can affect network structure and design: flight frequency, aircraft size, prices, aircraft velocity, takeoff/landing time, random delays, consumer preferences, costs per seat-mile and seat-day, demand and route-lengths.

LN show that in principle almost any network structure is optimal; thus, depending the parameters, it can be optimal to operate a $\mathrm{HS}$ or $\mathrm{P} 2 \mathrm{P}$ or sub-tour network. We extend their model to show why it may have been optimal for legacy carriers' to operate HS networks and why later LCC's chose sub-tour networks (contrary to common perceptions, LCCs do not operate P2P networks (Hussain (2003)). More subtly, LCC's P2P network is optimal and profitable only against the backdrop of HS networks. The model allows a comparison of legacy carriers' and LCCs' flight

\footnotetext{
${ }^{7}$ According to Credit Sights, Southwest, due to its timely fuel hedging, had the lowest year-on-year growth in fuel costs in 2005 ( $16 \%$ versus the next lowest, Alaska Air's 36\% and far below the maximum, US Air's $69 \%$ ) and has the lowest operating cost in the industry for its principal aircraft the Boeing 737-700. Heskett (2003) identifies some aspects of Southwest's superior management which contribute to its fast turnaround times and greater flight utilization, which are both being undermined following 9-11 and as Southwest expands.

${ }^{8}$ As we show below, there is nothing special about the choice of LCC's homogeneous aircrafts- it is the direct consequence of operating a network with uniform route-length. In contrast, because legacy carriers operate a network over routes of varying route-lengths, these necessarily must have heterogeneous aircrafts. For example, in 2005, indicating stage length in miles in parentheses, Southwest had 194 Boeing 737-300s (498), 25 Boeing 737-500s (368) and 218 Boeing 737-700s (779); Jet Blue had 80 Airbus A320s (1446), and Delta had 8 Boeing 777s (3749), 12 Boeing 767-200s (1069), 85 Boeing 767-300s (2454), 21 Boeing 767-400s (1787), 64 Boeing 757-200s (1314), 118 MD-88s (558), 16 MD-90s (836), 39 Boeing 737-1/200s (542), 21 Boeing 737-300s (432) and 70 Boeing 737-800s (1094).
} 
frequencies, aircraft sizes, prices, cost per seat-mile, cost per seat-day, total fixed and variable costs, revenues, profits, and social welfare.

We show the LCCs will operate smaller aircrafts with higher frequencies. For some routes, the higher frequencies, which lead to shorter wait times between flights, and shorter travel times (owing to, for some O-D city pairs, LCCs providing direct service instead of legacy carriers' service with connection), implies that LCCs may charge higher prices due to passengers on these routes being less inconvenienced relative to HS service. In contrast, for other routes, despite the overall higher frequencies, the longer travel times in the sub-tour routings, inconvenience passengers, which the LCCs compensate through lower prices. Thus, owing to how passengers are routed, LCCs do not necessarily charge lower prices in all routes, which has obvious implications for comparisons of fares across carriers: our model shows that route-specific prices are a function of (amongst others) not only frequency but also network connectivity.

As such it's not clear whether LCCs, despite lower fares, will raise social welfare. In fact, as we show, LCCs can theoretically lower social welfare, and provides an answer to Borenstein's (1992) question "What type or degree of government intervention will maximize social welfare?": restrict entry of airlines operating the 'low cost carrier' business model. Our analysis of route-specific prices provides an explanation for why entry by LCCs lowers legacy carriers' prices even in markets where there is no direct competition (which has been cited as a salubrious outcome of competition). When LCCs enter a route, the lower demand for legacy carriers results in these lowering flight frequencies which leads to longer wait times between flights, for which passengers are compensated through lower prices. In a HS network, flights carry both intra route and inter route passengers, the latter being those traveling to the hub to continue on to a destination which may not be served by LCCs. The lower frequency on direct competition routes will also impact passengers ultimately traveling to non-competition routes. Thus, these passengers must also be compensated by lower prices so that prices also decrease on routes without direct competition from LCCs.

Our model gives a new perspective on whether legacy carriers practice predatory pricing (Bamberger and Carlton (2006), Eckert and West (2006)). When LCCs enter a route, legacy carriers optimally lower frequency and therefore prices; conversely, if a LCC exits the route, legacy carriers optimally raise frequency and therefore prices. To an outside observer, oblivious of optimal network design, this will appear to predatory pricing when in fact it is the direct consequence of optimal network redesign.

Our model attempts an answer to another question raised in Borenstein (1992): "What equilibrium will evolve in the industry and what will be the speed and path of transition to that equilibrium?". We show that under the current deregulation regime, there is no equilibrium. This is because, firstly, in response to entry from LCCs, legacy carriers may deviate from a HS network to a non-HS network; secondly, as LCCs expand, they too must deviate from a sub-tour network to a HS network (Hussain (2006), using measures of network structure in Berry (2004) shows that this has already begin occurring). Without restrictions on entry by non-HS carriers, the cycle of HS networks being undermined by non-HS networks will be repeated such that there may be no network equilibrium,.

The rest of this paper is organized as follows: Section 2 presents LN index of network structure, section 3 presents our extension of LN to model optimal network structure and design for the deregulated U.S. airline industry, Section 4 presents an analysis of the model, and Section 5 concludes.

\section{LN (1998) Index of Network Structure}

LN develop an index of network structure that can be used as an argument in an endogenous network structure and design model. An even number of cities $n>0$ are equi-spaced on a circle with uniform demand for travel between all city pairs. For an O-D city pair $i, j$, denote a passenger 
flight by $i \rightarrow j$ and an empty flight carrying no passengers by $\{i \rightarrow j\}$. Assume all flights operate with exogenously given (daily) flight frequency $f$. Then $k=\{0,1,2, . ., n / 2, n\}$ is an index of network structure, which are discussed below.

\section{$2.1 k=0$ : Index of Point-to-Point (P2P) Network}

The following flight itinerary enables all passengers to travel directly between O-D cities:

$$
\begin{aligned}
& \text { for } i=1, . .,(n-1) \\
& \quad \text { for } j=(i+1), . ., n \\
& \quad i \rightarrow j \\
& \quad j \rightarrow i \\
& \quad \text { end } \\
& \quad\{i \rightarrow(i+1)\} \\
& \text { end } \\
& \{(n-1) \rightarrow 1\}
\end{aligned}
$$

Figure 1 illustrates the $k=0$ network for $n=4$ cities: passenger flights travel along the chord connecting O-D cities and empty flights travel along the circumference:

$$
\begin{aligned}
& 1 \rightarrow 2 \rightarrow 1 \\
& 1 \rightarrow 3 \rightarrow 1 \\
& 1 \rightarrow 4 \rightarrow 1 \\
&\{1 \rightarrow 2\} \\
& 2 \rightarrow 3 \rightarrow 2 \\
& 2 \rightarrow 4 \rightarrow 2 \\
&\{2 \rightarrow 3\} \\
& 3 \rightarrow 4 \rightarrow 3 \\
&\{3 \rightarrow 1\}
\end{aligned}
$$

Observe that the sum of the distances traveled by empty flights along the circumference is always $2 \pi r$.

\section{$2.20<k<n / 2$ : Index of Sub-Tour Network}

In a sub-tour network, passengers may be transported to their destination via intermediate stops. For tractability, consider first the HS network (a sub-tour network $k=1$ ) followed by other cases.

\subsection{1 $k=1$ Index of Hub-and-Spoke (HS) Network}

A HS network $k=1$ network consists of $n / k$ sub-tours (i.e. the $n$ cities). Passenger flights depart from each city, travel to the hub and loop back (see Figure 2 (a)). Flights traveling to the hub carry passengers bound for all other $(n-1)$ cities who are exchanged at the hub and placed on flights returning to all cities. Thus, a returning flight carries passengers bound from all other $(n-1)$ cities.

\subsection{2 $1<k<n / 2$ : Index of Sub-Tour Network}

If $k>1$, the network consists of $n / k<n$ sub-tours. In each sub-tour, flights depart (say, clockwise) from one end of the sub-tour- the "first" city on that sub-tour- and make $(k-1)$ stops until the 

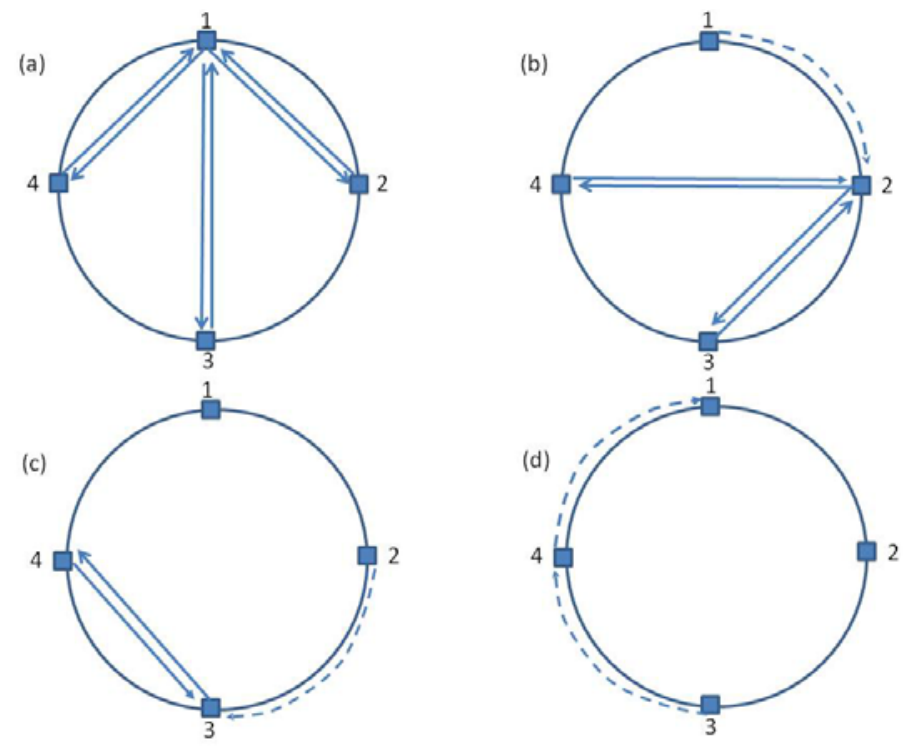

Figure 1: $k=0$ P2P Network for $n=4$

flight reaches the other $k$ th city- the "last" city on that sub-tour. From the first to the $(k-1)$ th city on the sub-tour, the flight picks up passengers bound for intra-tour cities, and, from all cities the flights picks up passengers bound for inter-tour cities. From the second to the $k$ th city on the sub-tour the flight drops off passengers bound for intra-tour cities; passengers bound for intra-tour cities are ferried to the center of the circle to be exchanged on the return flights from the remaining $(n / k)-1$ sub-tours. The flight returns from the center carrying passengers from the other subtours bound for cities in that sub-tour. Figures 2 (b), (c) illustrate the $n=4, k=2 n=6, k=2$ networks.

\section{$2.3 k=n$ : Index of Tour Network}

A tour network consists of a single sub-tour serving all cities. A flight departs from the first city, travels to every city picking up and dropping passengers, there being no inter-tour passengers, until it reaches the $n$th city (See Figure 2 (d) for $n=k=4$ ).

\section{Model: Setup}

We extend LN's to model the evolution of network structure and design in the post-deregulation U.S. airline industry.

\subsection{Assumptions}

A.1 $n>0$ exogenously given cities are served by an arbitrary number of carriers. The cities consist of two groups $A, B$ with $n_{a}$ cities in group $A$ and $n_{b}$ cities in group $B$. Cities in each group are equi-spaced on a circle with a common center (see Figure 3), where group $A$ has radius $R_{a}$ and group $B$ has radius $R_{b}$ with $R_{a}<<R_{b}$. Let $n_{a}, n_{b}$ be multiples of each other. 

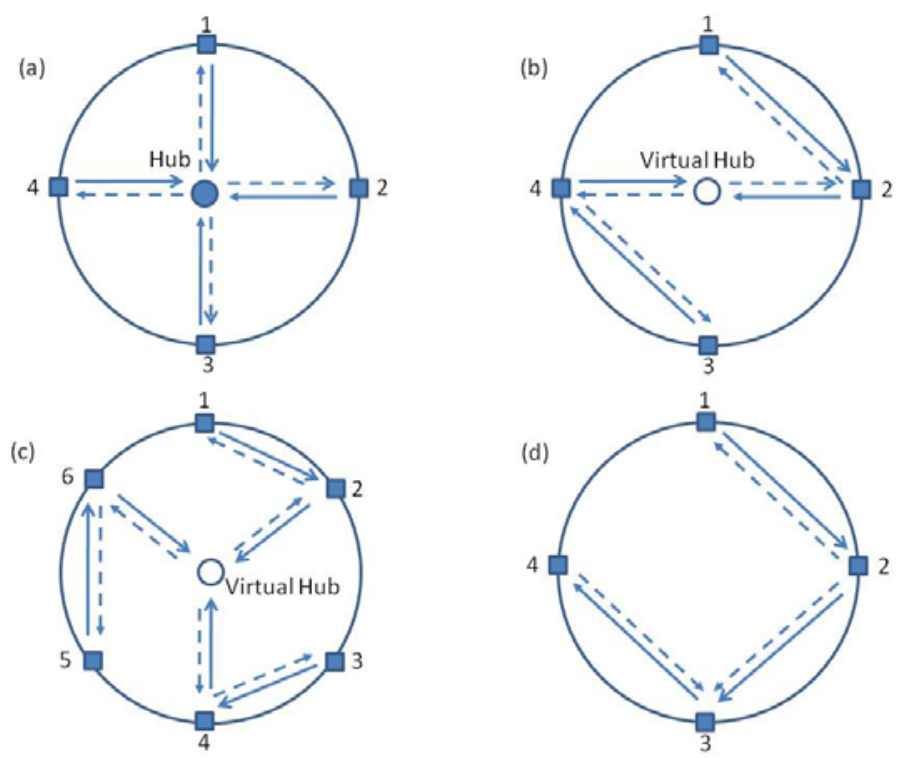

Figure 2: (a) $n=4, k=1$ Network (b) $n=4, k=2$ Network (c) $n=6, k=2$ Network (d) $n=k=4$ Network

A.2 Demand between origin-destination cities $i, j$ is denoted $d_{i j}, i \neq j$, where cities $i, j$ can be in either group $A$ or $B$. Demand is balanced and uniform ${ }^{9}$ :

$$
\begin{aligned}
d_{i i} & =d_{a a}, \forall i \in A \\
d_{i i} & =d_{b b}, \forall i \in B \\
d_{i j} & =d_{a b}=d_{b a}, \forall i, j \in A, B, i \neq j
\end{aligned}
$$

A.3 Flights operate with endogenously determined frequencies. In the $k=0$ network- owing to the way flights operate (see A.4 below)- there are four frequencies $f_{a a}(0), f_{b b}(0), f_{a b}(0), f_{b a}(0)$ corresponding to intra-group $A$, intra-group $B$, inter-group $A \rightarrow B$, and inter-group $B \rightarrow A$ travel markets. On the other hand, in $k \neq 0$ networks- again owing to how flights operate (see A.4 below)- there are two frequencies $f_{a}(k>0), f_{b}(k>0)$, where $f_{a}(k>0)$ encompasses intra-group $A$ and inter-group $A \rightarrow B$ travel markets and $f_{b}(k>0)$ encompasses intra-group $B$ and inter-group $B \rightarrow A$ travel markets.

A.4 Network structure is indexed by $k=\{0,1,2, . ., n / 2, n\}$ where $n=\min \left\{n_{a}, n_{b}\right\}$. Assume carriers operate a single network structure- for example, it cannot be that group $A$ has a $k=0$ network and group $B$ has a $k \neq 0$ network. The flight itineraries for a given $k$ differ from LN. In a $k=0$ network there are four distinct networks corresponding to each 'market': intra-group $A$, intra-group $B$, inter-group $A \rightarrow B$ and inter-group $B \rightarrow A$ travel. The following flight itinerary

\footnotetext{
${ }^{9}$ Combined with the assumption $R_{a}<<R_{b}$ A.1 and A.2 permit models of a variety of airlines and networks. For example, Southwest airlines 'cherry picks' routes with high-demand low-distance which can be modeled by $d_{a a}>d_{b b}, R_{a}<<R_{b}$.
} 


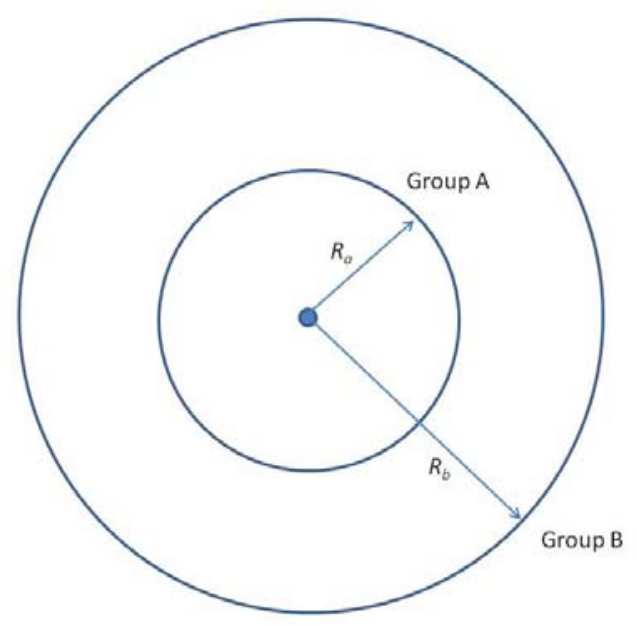

Figure 3: Groups $A$ and $B$

connects the intra-group $A$ travel market directly (flights operate with frequency $f_{a a}(0)$ ):

$$
\begin{aligned}
& \text { for } i=1, . .,\left(n_{a}-1\right) \\
& \quad \text { for } j=(i+1), . ., n_{a} \\
& \quad i \rightarrow j \\
& \quad j \rightarrow i \\
& \quad \text { end } \\
& \quad\{i \rightarrow(i+1)\} \\
& \text { end } \\
& \left\{\left(n_{a}-1\right) \rightarrow 1\right\}
\end{aligned}
$$

The following flight itinerary connects the intra-group $B$ travel market directly (flights operate with frequency $\left.f_{b b}(0)\right)$ :

$$
\begin{aligned}
& \text { for } i=1, . .,\left(n_{b}-1\right) \\
& \quad \text { for } j=(i+1), \ldots, n_{b} \\
& \qquad i \rightarrow j \\
& \quad j \rightarrow i \\
& \quad \text { end } \\
& \quad\{i \rightarrow(i+1)\} \\
& \text { end } \\
& \left\{\left(n_{b}-1\right) \rightarrow 1\right\}
\end{aligned}
$$

Denote group $A$ and $B$ 's common center with $C$ and denote city $i$ in group $G$ by $i_{\in G}$. The following itinerary connects inter-group $A \rightarrow B$ and $B \rightarrow A$ market directly: a flight departs from group $A$ because in a $k=0$ network the flight has to travel empty along the circumference of some group; airlines, seeking to minimize operations cost will operate the empty flight on the group with the 
smaller radius, which in this model is group $A$ :

$$
\begin{aligned}
& \text { for } i=1_{a}, . ., n_{a} \\
& \quad \text { for } j=1_{b}, . ., n_{b} \\
& \quad i_{a} \rightarrow j_{b} \\
& \quad j_{b} \rightarrow i_{a} \\
& \quad \text { end } \\
& \quad\left\{i_{a} \rightarrow\left(i_{a}+1\right)\right\} \\
& \text { end }
\end{aligned}
$$

where flights operate with frequency $f_{a b}(0)$ when departing from a group $A$ city and frequency $f_{b a}(0)$ when departing from a group $B$ city. Observe the same aircraft serves travel from group $A \rightarrow B$ and $B \rightarrow A$. Thus, in a $k=0$ network there are three aircraft sizes but four frequencies.

In a network $0<k<n / 2$ network flights depart from each of the $\left(n_{a} / k\right),\left(n_{b} / k\right)$ sub-tours in

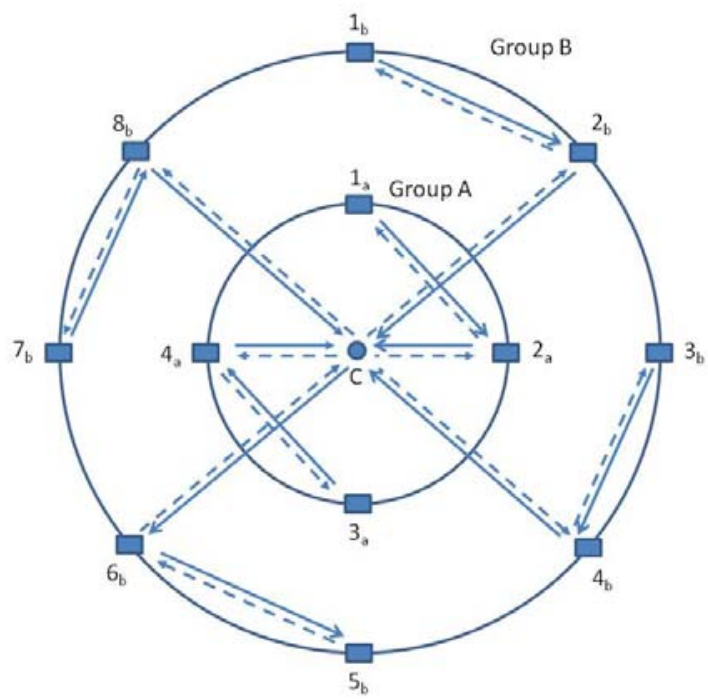

Figure 4: $k=2$ network for $n_{a}=4, n_{b}=8$

groups and $A$ and $B$ with frequencies $f_{a}(k), f_{b}(k)$ respectively, travel to the center where intragroup-inter-tour and inter-group passengers are exchanged. The flight itinerary for a tour network differs from LN in one respect: in this model inter-group passengers must be exchanged at the center- when the flight reaches the $k=\min \left\{n_{a}, n_{b}\right\}$ th city on the tour, it travels to the center where inter-group passengers are exchanged (see Figure 5).

A.5 Owing to network routings, a P2P network is served by three aircraft types, $S_{a a}(0), S_{b b}(0)$ and $S_{a b}(0)=S_{b a}(0)$ corresponding to intra-group $A$, intra-group $B$ and inter-group $A \rightarrow B \equiv B \rightarrow A$ travel markets, while $k \neq 0$ networks are served by two aircraft types, $S_{a}(k), S_{b}(k)$, corresponding to travel originating in group $A$ (which includes intra-group $A$ and inter-group $A \rightarrow B$ travel) and travel originating in group $B$ (which includes intra-group $B$ and inter-group $B \rightarrow A$ travel).

A.6 Aircraft velocity, takeoff/landing time, variable cost per seat mile and fixed cost per seat day 


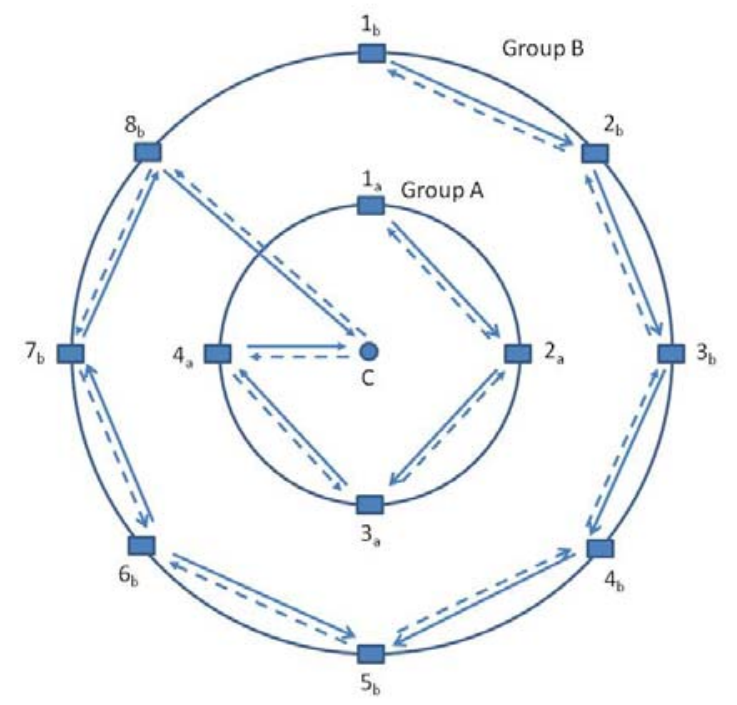

Figure 5: $k=4$ tour Network for Group $A$, Sub-Tour Network for Group $B$

are exogenous and independent of aircraft size or network structure ${ }^{10}$. Takeoff and landing each require $g / 2$ hours and are independent of the O-D city pair and $k$. There are economies of scale in variable cost per seat mile ${ }^{11} V C(k)$ and aircraft fixed cost per available seat-day $F C(k)$ is constant:

$$
\begin{aligned}
& V C(k)=\alpha+\beta / S(k) \\
& F C(k)=\gamma
\end{aligned}
$$

where $\alpha, \beta, \gamma>0$. The total variable cost $T V C(k)$ is the product of total seat miles $S M(k)$ and variable cost per seat mile $V C(k)$ and the total fixed cost $T F C(k)$ is the product of total seat days $S D(k)$ and fixed cost per seat day $F C(k)$ :

$$
\begin{aligned}
& T V C(k)=S M(k) V C(k) \\
& T F C(k)=S D(k) F C(k)
\end{aligned}
$$

where $S M(K)$ is equal to $S(K)$ times the total miles in a flight's itinerary, and, $S D(k)$ is the fleet size times $S(k)$ (i.e., the total number of seats). The total miles traveled by an aircraft and the fleet size are both functions of $k$.

A.7 Flights may be randomly delayed at takeoff or landing. Delay time is i.i.d exponential with parameter $\lambda$. Since the exponential distribution is gamma $(1, \lambda)$, the takeoff and landing delay times is distributed gamma $(2, \lambda)$. Assume carriers plan for delays by adding a 'planned delay' time $A_{\delta}$ in addition to the flight time where $P\left(X \geq A_{\delta}\right)=\delta$. Aircraft controllers are assumed to be cognizant of $A_{\delta}$ and hold the aircraft in a "holding pattern" until the buffer time is used up"

\footnotetext{
${ }^{10}$ See http://www.globalaircraft.org for data on aircraft velocity.

${ }^{11}$ For an excellent overview of cost per seat mile across carriers by type of aircrafts see CreditSight's report "Airlines: Legacy Aircraft Cost Disadvantag", February 2006.

${ }^{12}$ Daniels (1995) models and estimates congestion at hub airports. Mayer and Sinai (2002) study the sources of congestion and delays.
} 
A.8 Consumer preference for travel between O-D cities $i, j$ is represented by a utility function which is linear in the benefit of travel and the disutility from price, travel time, wait times between flights and the possible inconvenience of traveling from a secondary airport such as Providence, RI instead of Boston, MA:

$$
U_{i j}(k)=B_{i j}-p_{i j}(k)-t T_{i j}(k)-w W_{i j}(k)-\Delta_{i j}
$$

$B_{i j}$ is the benefit of travel, $p_{i j}(k)$ is the price; $t$ is travel cost per hour and $T_{i j}(k)$ is the total passenger travel time; $W_{i j}(k)$ is the passenger's average wait times between flights ${ }^{13}$ and $w$ the waiting cost per hour; $\Delta_{i j}$ is the possible cost of inconvenience if the consumer travels from a 'secondary' airport. The total passenger time is the sum of flight time plus takeoff/landing time plus planned delay time:

$$
T_{i j}(k)=F_{i j}(k)+G_{i j}(k)+D_{i j}(k)
$$

Consumers have common reservation utility $\bar{U}_{i j}$ and travel if $U_{i j}(k) \geq \bar{U}_{i j}$.

A.9 Carriers practice yield management and set prices to extract all consumer surplus:

$$
p_{i j}(k)=B_{i j}-t T_{i j}(k)-w W_{i j}(k)-\Delta_{i j}-\bar{U}_{i j}
$$

Price is a function of $k$ because carriers must compensate travelers for (amongst others) longer travel and wait times, which are functions of $k$.

A.10 The total network overhead cost of flight coordination and management $O(k \mid n)$ has economies of scope: $O\left(k \mid n_{a}\right)+O\left(k \mid n_{b}\right)>O\left(k \mid n_{a}+n_{b}\right)$; i.e. it's cheaper to manage the network $k$ over both groups $A$ and $B$ together than separately.

\section{$3.2 \quad$ Objective}

Carriers choose network structure $k$ and network design- $f(k), S(k), p(k)$ - to maximize profits subject to all travel markets having a common $k$ and (trivially) all consumers traveling. The model is solved in several steps: first, given $k$ carriers choose $S(k)$; second, given $k, S(K)$ carriers choose optimal $f(k)$; third, given $S(k), f(k)$ carriers choose $k$ to maximize total network profits.

Denote profits between the O-D city pair $i, j$ by $\Pi_{i j}(k)$. Summing across all possible O-D city pairs yields the total network profits:

$$
\Pi(k)=\sum_{i}^{n} \sum_{j \neq i}^{n} \Pi_{i j}(k)=\sum_{i}^{n} \sum_{j \neq i}^{n}\left\{R_{i j}(k)-V C_{i j}(k)-F C_{i j}(k)\right\}-O(k \mid n)
$$

$R_{i j}$ is:

$$
R_{i j}(k)=p_{i j}(k) d_{i j}=\left\{B_{i j}-\Delta_{i j}-\bar{U}_{i j}-t T_{i j}(k)-w W_{i j}(k)\right\} d_{i j}
$$

Substituting and re-arranging:

$$
\begin{aligned}
\Pi(k)= & \sum_{i} \sum_{j \neq i}\left[B_{i j}-\Delta_{i j}-\bar{U}_{i j}\right] d_{i j} \\
& -\sum_{i} \sum_{j \neq i}\left[t T_{i j}(k)+w W_{i j}(k)\right] d_{i j} \\
& -\sum_{i} \sum_{j \neq i} T V C_{i j}(k)-\sum_{i} \sum_{j \neq i} T F C_{i j}(k)-O(k \mid n) \\
& \ni U_{i j}(k) \geq \bar{U}_{i j}
\end{aligned}
$$

\footnotetext{
${ }^{13}$ For inter-group travel this includes the waiting time at the origin and the center. One can relax this assumption so that only waiting times at the origin matters.
} 
The first line is independent of $k$; thus, maximizing profits is equivalent to minimizing the sum of the second and third lines denoted $C(k)$ :

$$
\begin{aligned}
C(k)= & t \sum_{i} \sum_{j \neq i} T_{i j}(k) d_{i j}+w \sum_{i} \sum_{j \neq i} W_{i j}(k) d_{i j} \\
& +\sum_{i} \sum_{j \neq i} T V C_{i j}(k)+\sum_{i} \sum_{j \neq i} T F C_{i j}(k)+O(k \mid n) \\
C(k)= & \underbrace{t T(k)+w W(k)}_{\text {Passengers Cost }}+\underbrace{T V C(k)+T F C(k)+O(k \mid n)}_{\text {Carriers Cost }}
\end{aligned}
$$

Carriers choose $k, f(k), S(k), p(k)$ to minimize the sum of passengers' total cost of travel time and airlines' total cost of travel.

For the $k=0$ network, $C(k)$ is equal to passenger plus carriers' cost in four separate 'network routings': intra-group $A$, intra-group $B$, inter-group $A \rightarrow B$ and inter-group $B \rightarrow A$ routings (see Figure 6 (a), (b)). In the $k>0$ network, $C(k)$ is equal to passenger plus carriers' cost in two separate 'network routings': for travel originating in group $A$ - which consists of intra-group $A$ and inter-group $A \rightarrow B$ travel- and originating in group $B$ - which consists of intra-group $B$ and intergroup $B \rightarrow A$ travel. For $k>0$ networks, intra-group travel consists of intra-tour travel (Figure 7 (a)) and inter-tour travel (Figure 7 (b)); inter-group travel is illustrated in Figure 8.

Decompose $C(K)$ for a 'network routing' (suppressing the network overhead cost $O(k \mid n)$ ):

$$
\begin{aligned}
C(k)= & t T(k)+w W(k)+T V C(k)+T F C(k) \\
= & t(F(k)+G(k)+D(K))+w W(k)+S M(k) V C(k)+S D(K) F C(k) \\
= & t(F(k)+G(k)+D(K))+w W(k) \\
& +S(k) f(k) \text { Miles Traveled } V C(k)+S D(K) F C(k) \\
= & t(F(k)+G(k)+D(K))+w W(k) \\
& +S(k) f(k) \text { Miles Traveled } V C(k)+S(k) \text { Fleet Size } F C(k)
\end{aligned}
$$

Sections 3.3 through 3.7 derive expressions for $F(k), G(k), D(K), W(k), S(K), f(k), S M(k), S D(k)$, miles traveled and fleet size.

For each expression, we consider $k=0$ and $k>0$ networks separately; for a given $k$, we examine specific 'network routings'; for a given 'network routing' we examine $F(k), G(k), D(k), W(k), S(k)$, $f(k), S M(k), S D(k)$ between arbitrary O-D city pairs $i, j$. Expressions for $F_{i j}(k), G_{i j}(k), D_{i j}(k)$, $W_{i j}(k), S_{i j}(k), f_{i j}(k), S M_{i j}(k), S D_{i j}(k)$ are aggregated over all O-D city pairs in that network routing which are in turn aggregated across all network routings for that network structure $k$ to yield $F(k), G(k), D(k), W(k), S(k), f(k), S M(k), S D(k)$. The interested reader can skip the derivation below and go directly to section 4 for analysis of the model.

\subsection{Passenger Travel Time $T(k)$}

Total travel time for a passenger traveling from an origin city in group $i, O_{i}$, to a destination city in group $j, D_{j}$, consists of total passenger flight plus takeoff/landing plus planned delay times. Passenger flight travel time is not the same as total flight travel time; in the $k=0$ network for instance in some portions of the itinerary the flight travels empty along the circumference.

\subsubsection{Passenger Flight Time $F(k)$}

Denote total passenger flight time by TFT. 


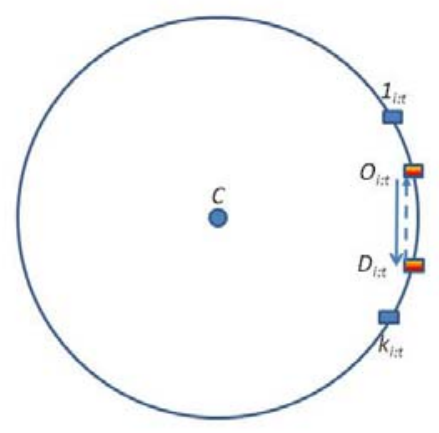

(a)

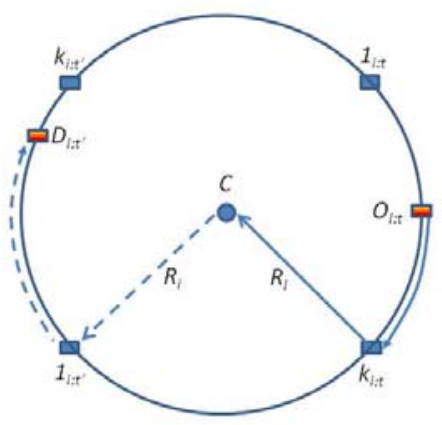

(b)

Figure 6: $k=0$ Network: (a) Intra-group Travel (b) Inter-group Travel

\section{$k=0$ Network TFT:}

$k=0$ Intra-Group Travel TFT: The O-D city pair $\left(O_{i}, D_{i}\right)$ is directly connected by a chord of length $2 R_{i} \sin (\theta / 2)$ where $\theta$ is the sub-tending angle for the arc connecting $O_{i}, D_{i}$ where $\theta=$ $s / R_{i}, s=$ length of the $\operatorname{arc}=2 \pi R_{i}\left|O_{i}-D_{i}\right| / n_{i}$ and $\theta=2 \pi R_{i}\left|O_{i}-D_{i}\right| / R_{i} n_{i}$ so that the chord connecting $O_{i}, D_{i}$ has length $2 R_{i} \sin \left(\pi\left|O_{i}-D_{i}\right| / n_{i}\right)$. Dividing by velocity $v$ gives the flight time between $\left(O_{i}, D_{i}\right)$ :

$$
F_{\left(O_{i}, D_{i}\right)}(k=0)=\frac{2 R_{i}}{v} \sin \left(\pi\left|O_{i}-D_{i}\right| / n_{i}\right)
$$

Aggregating over all O-D pairs in group $i$ and multiplying by 2 (since flights loop back to the origin city) gives the total intra-group $i$ passengers TFT:

$$
F_{i i}(k=0)=2 \sum_{O_{i}}^{n_{i}} \sum_{D_{i}}^{n_{i}} F_{\left(O_{i}, D_{i}\right)} d_{i i}=\cot \left(\pi / 2 n_{i}\right) R_{i} n_{i} d_{i i} / v
$$

Setting $i=A, B$ yields $F_{a a}, F_{b b}$ :

$$
\begin{gathered}
F_{a a}(k=0)=\cot \left(\pi / 2 n_{a}\right) R_{a} n_{a} d_{a a} / v \\
F_{b b}(k=0)=\cot \left(\pi / 2 n_{b}\right) R_{b} n_{b} d_{b b} / v
\end{gathered}
$$

$k=0$ Inter Group Travel TFT: Inter-group passengers travel from $O_{i}$ along the radius $R_{i}$ to the center and along the radius $R j$ to $D_{j}$. Thus:

$$
F_{\left(O_{i}, D_{j}\right)}(k=0)=\left(R_{i}+R_{j}\right) / v
$$

Aggregating over all $O_{i}, D_{j}$ in the inter-group $i, j$ network routing:

$$
F_{i j}(k=0)=\sum_{O_{i}}^{n_{i}} \sum_{D_{j}}^{n_{j}} F_{\left(O_{i}, D_{j}\right)} d_{i j}=n_{i} n_{j}\left(R_{i}+R_{j}\right) d_{i j} / v
$$




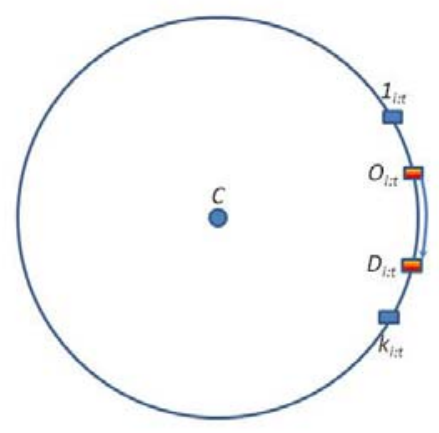

(a)

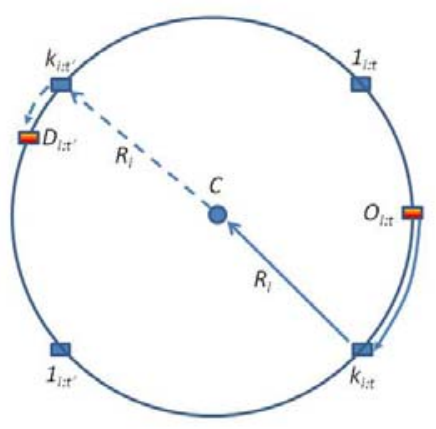

(b)

Figure 7: $k>0$ Network: (a) Intra-group Intra-Tour Travel (b) Intra-group Inter-Tour Travel

Setting $i, j=A, B$ and $i, j=B, A$ yields:

$$
\begin{aligned}
& F_{a b}(k=0)=n_{a} n_{b}\left(R_{a}+R_{b}\right) d_{a b} / v \\
& F_{b a}(k=0)=n_{b} n_{a}\left(R_{b}+R_{a}\right) d_{b a} / v
\end{aligned}
$$

TFT in $k=0$ Network: Summing up over intra group and inter group network routings yields TFT in the $k=0$ network:

$$
\begin{aligned}
F(k=0) & =F_{a a}(k=0)+F_{b b}(k=0)+2 F_{a b}(k=0) \\
& =2\left\{R_{a} n_{a} d_{a a} \cot \left(\pi / 2 n_{a}\right)+R_{b} n_{b} d_{b b} \cot \left(\pi / 2 n_{b}\right)+n_{a} n_{b}\left(R_{a}+R_{b}\right) d_{a b}\right\} / v
\end{aligned}
$$

\section{$k>0$ Network TFT:}

$k>0$ Intra-Group Travel TFT: Consider first intra-group intra-tour travel between the O-D city pair $O_{i: t}, D_{i: t}$, where $D_{i: t}=O_{i: t}+1, \ldots, k_{i: t}$. The distance between adjacent cities in group $i$ is $2 \pi R_{i} / n_{i}$ and therefore the distance between $\left(O_{i: t}, D_{i: t}\right)$ is $\left|O_{i: t}-O_{D_{i: t}}\right| 2 \pi R / n_{i}$ which divided by velocity $v$ gives the passenger TFT:

$$
F_{\left(O_{i: t}, D_{i: t}\right)}=2 \pi R_{i}\left|O_{i: t}-D_{i: t}\right| / n_{i} v
$$

Demand being bi-directional between $\left(O_{i: t}, D_{i: t}\right)$ the TFT for intra-group intra-tour travel is twice the expression above aggregated over all O-D city pairs in the intra-group intra-tour network rout- 


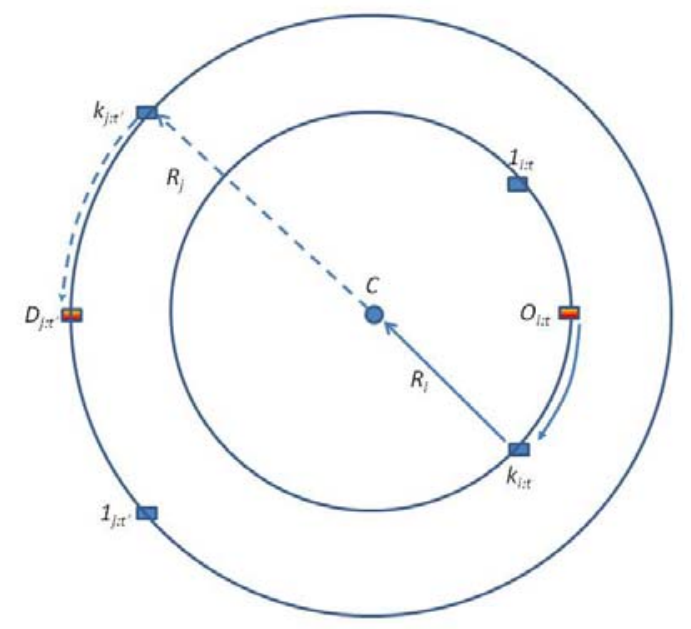

Figure 8: $k>0$ Network: Inter-Group Travel

ing:

$$
\begin{aligned}
F_{i i}\left(k>0 \mid O_{i: t}, D_{i: t}\right) & =\sum_{O_{i: t}}^{n_{i}} \sum_{D_{i: t}}^{n_{i}-1} F_{\left(O_{i: t}, D_{i: t}\right)}=\left(2 n_{i} d_{i i} / k\right) \sum_{O_{i: t}}^{k-1} \sum_{D_{i: t}}^{k} F_{\left(O_{i: t}, D_{i: t}\right)} \\
& =2\left(n_{i} d_{i i} / k\right) \sum_{O_{i: t}}^{k-1} \sum_{D_{i: t}}^{k} \frac{2 \pi R_{i}}{n_{i} v}\left|O_{i: t}-D_{i: t}\right| \\
& =\left(4 \pi R_{i} d_{i i} / v\right) \sum_{O_{i: t}}^{k-1} \sum_{D_{i: t}}^{k}\left|O_{i: t}-D_{i: t}\right| \\
& =2 \pi R_{i} d_{i i}\left(k^{2}-1\right) / 3 v
\end{aligned}
$$

Now consider intra-group inter-tour TFT between the O-D city pair $\left(O_{i: t}, D_{i: t^{\prime}}\right)$. The distance between cities $O_{i: t}$ and $k_{i: t}$ is $\left(2 \pi R_{i} / n_{i}\right)\left(k_{i: t}-O_{i: t}\right)$; the distance between cities $k_{i: t}$ and $k_{i: t^{\prime}}$ is $2 R_{i}$; and the distance between cities $k_{i: t^{\prime}}$ and $D_{i: t^{\prime}}$ is $\left(k_{i: t^{\prime}}-D_{i: t^{\prime}}\right) 2 \pi R_{i} / n_{i}$. Summing these and dividing by velocity:

$$
F_{\left(O_{i: t}, D_{i: t^{\prime}}\right)}(k>0)=\frac{2 \pi R_{i}}{n_{i} v}\left(k_{i: t}-O_{i: t}\right)+\frac{2 R_{i}}{v}+\frac{2 \pi R_{i}}{n_{i} v}\left(k_{i: t^{\prime}}-D_{i: t^{\prime}}\right)
$$

There are $n_{i} / k$ sub tours sending passengers to $\left(n_{i} / k\right)-1$ other sub tours. Thus the total intra-group $i$ inter-tour TFT is:

$$
\begin{aligned}
F_{i i}\left(k>0 \mid O_{i: t}, D_{i: t^{\prime}}\right) & =\sum_{O_{i: t}}^{n_{i}} \sum_{D_{i: t^{\prime}}}^{n_{i}-1} F_{\left(O_{i: t}, D_{i: t^{\prime}}\right)}=d_{i i}\left(\frac{n_{i}}{k}-1\right) \frac{n_{i}}{k} \sum_{O_{i: t}}^{k} \sum_{D_{i: t^{\prime}}}^{k} F_{\left(O_{i: t}, D_{i: t^{\prime}}\right)} \\
& =d_{i i}\left(\frac{n_{i}}{k}-1\right) \frac{n_{i}}{k} \sum_{O_{i: t}}^{k} \sum_{D_{i: t^{\prime}}}^{k} 2 R_{i}\left\{\frac{\pi}{n_{i}}\left(k_{i: t}-O_{i: t} \mid+1+\frac{\pi}{n_{i}}\left(k_{i: t^{\prime}}-D_{i: t^{\prime}}\right)\right\} / v\right. \\
& =2 k R_{i} d_{i i} n_{i}\left\{2 \pi k+n_{i}-\pi(k+1)\right\} / v
\end{aligned}
$$


Aggregating $F_{i i}\left(k>0 \mid O_{i: t}, D_{i: t}\right), F_{\left(O_{i: t}, D_{i: t^{\prime}}\right)}(k>0)$ over all intra-group $i$ O-D city pairs yields intra-group $i$ TFT:

$$
\begin{aligned}
F_{i i}(k>0) & =\sum_{O_{i: t}}^{n_{i}} \sum_{D_{i: t}}^{n_{i}-1} F_{\left(O_{i: t}, D_{i: t}\right)}+\sum_{O_{i: t}}^{n_{i}} \sum_{D_{i: t^{\prime}}}^{n_{i}-1} F_{\left(O_{i: t}, D_{i: t^{\prime}}\right)} \\
& =\left(2 \pi R_{i} d_{i i}\left\{(k-1)\left(n_{i}-k\right)+\left(k^{2}-1\right) / 3\right\}+2 R_{i} d_{i i} n_{i}\left(n_{i}-k\right)\right) / v
\end{aligned}
$$

Setting $i=A, B$ :

$$
\begin{aligned}
F_{a a}(k>0) & =\left(2 \pi R_{a} d_{a a}\left\{(k-1)\left(n_{a}-k\right)+\left(k^{2}-1\right) / 3\right\}+2 R_{a} d_{a a} n_{a}\left(n_{a}-k\right)\right) / v \\
F_{b b}(k>0) & =\left(2 \pi R_{b} d_{b b}\left\{(k-1)\left(n_{b}-k\right)+\left(k^{2}-1\right) / 3\right\}+2 R_{b} d_{b b} n_{b}\left(n_{b}-k\right)\right) / v
\end{aligned}
$$

Inter-Group Travel TFT: Consider inter-group travel between $\left(O_{i: t}, D_{j: t^{\prime}}\right)$. The distance between cities $O_{i: t}$ and $k_{i: t}$ is $\left(2 \pi R_{i} / n_{i}\right)\left(k_{i: t}-O_{i: t}\right)$; the distance between cities $k_{i: t}$ and $k_{j: t^{\prime}}$ is $R_{i}+R_{j}$; the distance between cities $k_{j: t^{\prime}}$ and $D_{j: t^{\prime}}$ is $\left(k_{j: t^{\prime}}-D_{j: t^{\prime}}\right) 2 \pi R_{j} / n_{j}$. Summing and dividing by velocity:

$$
F_{\left(O_{i: t}, D_{j: t^{\prime}}\right)}(k>0)=\frac{2 \pi R_{i}}{n_{i} v}\left(k_{i: t}-O_{i: t}\right)+\frac{R_{i}+R_{j}}{v}+\frac{2 \pi R_{j}}{n_{j} v}\left(k_{j: t^{\prime}}-D_{j: t^{\prime}}\right)
$$

$d_{i j}$ passengers from $n_{i} / k$ sub-tours in group $i$ travel to $n_{j} / k$ sub-tours in group $j$. The TFT for inter group $i, j$ travel is:

$$
\begin{aligned}
F_{i j}(k>0) & =d_{i j} \frac{n_{i}}{k} \frac{n_{j}}{k} \sum_{O_{i}}^{n_{i}} \sum_{D_{j}}^{n_{j}} F_{\left(O_{i}, D_{j}\right)} \\
& =d_{i j}\left\{\pi(k-1)\left(n_{j} R_{i}+n_{a} R_{j}\right)+n_{i} n_{j}\left(R_{i}+R_{j}\right)\right\} / v
\end{aligned}
$$

Thus:

$$
\begin{aligned}
& F_{a b}(k>0)=d_{a b}\left(\pi(k-1)\left(n_{b} R_{a}+n_{a} R_{b}\right)+n_{a} n_{b}\left(R_{a}+R_{b}\right)\right) / v \\
& F_{b a}(k>0)=d_{b a}\left(\pi(k-1)\left(n_{b} R_{a}+n_{a} R_{b}\right)+n_{a} n_{b}\left(R_{a}+R_{b}\right)\right) / v
\end{aligned}
$$

$k>0$ Network TFT: Aggregating over all O-D city pairs in the intra-group and inter-group network routings yields the TFT in a $k>0$ network:

$$
\begin{aligned}
F(k>0)= & F_{a a}(k>0)+F_{b b}(k>0)+2 F_{a b}(k>0) \\
= & \left.2\left(\pi R_{a} d_{a a}\left\{(k-1)\left(n_{a}-k\right)+\left(k^{2}-1\right) / 3\right\}+R_{a} d_{a a} n_{a}\left(n_{a}-k\right)\right)\right) / v \\
& +2\left(\pi R_{b} d_{b b}\left\{(k-1)\left(n_{b}-k\right)+\left(k^{2}-1\right) / 3\right\}+R_{b} d_{b b} n_{b}\left(n_{b}-k\right)\right) / v \\
& +2 d_{a b}\left(\pi(k-1)\left(n_{b} R_{a}+n_{a} R_{b}\right)+n_{a} n_{b}\left(R_{a}+R_{b}\right)\right) / v
\end{aligned}
$$

\subsubsection{Passenger Takeoff and Landing Time $G(k)$}

Denote the total takeoff and landing time by TLT.

$k=0$ Network TLT:

Intra Group Travel TLT: Since each O-D pair is directly connected:

$$
G_{\left(O_{i}, D_{i}\right)}(k=0)=g
$$


Aggregating over all intra-group O-D city pairs yields the intra group $i$ TLT:

$$
G_{i i}(k=0)=\sum_{O_{i}}^{n_{i}} \sum_{D_{i}}^{n_{i}} G_{\left(O_{i}, D_{i}\right)} d_{i i}=g n_{i}\left(n_{i}-1\right) d_{i i}
$$

Setting $i=A, B$ yields:

$$
\begin{aligned}
G_{a a}(k=0) & =g n_{a}\left(n_{a}-1\right) d_{a a} \\
G_{b b}(k=0) & =g n_{b}\left(n_{b}-1\right) d_{b b}
\end{aligned}
$$

Inter-Group Travel TLT: Since each O-D pair is directly connected:

$$
G_{O_{i}, D_{j}}(k=0)=g
$$

The TLT for all passengers' inter group $i$ to group $j$ travel is:

$$
G_{i j}(k=0)=\sum_{O_{i}}^{n_{i}} \sum_{D_{j}}^{n_{j}} G_{\left(O_{i}, D_{j}\right)} d_{i j}=g n_{i} n_{j} d_{i j}
$$

which yields:

$$
\begin{aligned}
G_{a b}(k=0) & =g n_{a} n_{b} d_{a b} \\
G_{b a}(k=0) & =g n_{b} n_{a} d_{b a}
\end{aligned}
$$

$k=0$ Network TLT: Aggregating over all O-D city pairs yields the TLT in the $k=0$ network:

$$
\begin{aligned}
G(k=0) & =G_{a a}(k=0)+G_{b b}(k=0)+2 G_{a b}(k=0) \\
& =g n_{a}\left(n_{a}-1\right) d_{a a}+g n_{b}\left(n_{b}-1\right) d_{b b}+2 g n_{a} n_{b} d_{a b}
\end{aligned}
$$

\section{$k>0$ Network TLT:}

Intra-Group Travel TLT: Consider the TLT for intra-group intra-tour travel between cities $O_{i: t}, D_{i: t}$ : takeoff from $O_{i: t}$ is $g / 2$ hours; $g\left|D_{i: t}-O_{i: t}-1\right|$ hours for the $\left|D_{i: t}-O_{i: t}-1\right|$ stops between cities $O_{i: t}$ and $D_{i: t} ; g / 2$ hours for the landing at city $D_{i: t}$. Summing these yields:

$$
G_{\left(O_{i: t}, D_{i: t}\right)}(k>0)=g / 2+\left|D_{i: t}-O_{i: t}-1\right| g+g / 2=g\left|D_{i: t}-O_{i: t}\right|
$$

The TLT for intra-group inter-tour travel between cities $O_{i: t}, D_{i: t^{\prime}}$ is: $g\left|k_{i: t}-O_{i: t}\right|$ hours between cities $O_{i: t}$ and $k_{i: t} ; g$ hours from city $k_{i: t}$ to the center; $g$ hours from the center to city $k_{i: t^{\prime}}$; and $g\left|k_{i: t^{\prime}}-D_{i: t}\right|$ hours from city $k_{i: t^{\prime}}$ to city $D_{i: t^{\prime}}$. Summing these and multiplying by 2 for the bi-directional demand yields:

$$
G_{\left(O_{i: t}, D_{i: t^{\prime}}\right)}(k>0)=2 g k+2 g-g\left(O_{i: t}+D_{i: t^{\prime}}\right)
$$

With $\left(n_{i} / k\right)\left(\left(n_{i} / k\right)-1\right)$ sub-tours the total intra group $i$ TLT is:

$$
\begin{aligned}
G_{i i}(k>0)= & 2 d_{i i} \frac{n_{i}}{k} \sum_{O_{i: t}}^{k-1} \sum_{D_{i: t}}^{k} G_{\left(O_{i: t}, D_{i: t}\right)} \\
& +d_{i i}\left(\frac{n_{i}}{k}-1\right) \frac{n_{i}}{k} \sum_{O_{i: t}}^{k} \sum_{D_{i: t^{\prime}}}^{k} G_{\left(O_{i: t}, D_{i: t^{\prime}}\right)} \\
= & d_{i i} n_{i} g\left(k^{2}-1\right) / 3+d_{i i} n_{i} g\left(n_{i}-k\right)(k+1)
\end{aligned}
$$


Setting $i=A, B$ the TLT for intra group $A, B$ travel is:

$$
\begin{aligned}
G_{a a}(k>0) & =d_{a a} n_{a} g\left(k^{2}-1\right) / 3+d_{a a} n_{a} g\left(n_{a}-k\right)(k+1) \\
G_{b b}(k>0) & =d_{b b} n_{b} g\left(k^{2}-1\right) / 3+d_{b b} n_{b} g\left(n_{b}-k\right)(k+1)
\end{aligned}
$$

Inter-Group Travel TLT: The TLT for a passenger traveling between cities $\left(O_{i: t}, D_{j: t^{\prime}}\right)$ is:

$$
G_{\left(O_{i}, D_{j}\right)}=2 g k+2 g-g\left(O_{i}+D_{j}\right)
$$

Aggregating over all inter-group O-D city pairs:

$$
G_{i j}(k>0)=d_{i j} \frac{n_{i}}{k} \frac{n_{j}}{k} \sum_{O_{i}=1}^{n_{i}} \sum_{D_{j}=1}^{k} G_{\left(O_{i}, D_{i}\right)}=d_{i j} n_{i} n_{j}(k+1) g
$$

and:

$$
\begin{aligned}
G_{a b}(k>0) & =d_{a b} n_{a} n_{b}(k+1) g \\
G_{b a}(k>0) & =d_{b a} n_{b} n_{a}(k+1) g
\end{aligned}
$$

$k>0$ Network TLT: The TLT in a $k>0$ network is:

$$
\begin{aligned}
G(k>0)= & G_{a a}(k>0)+G_{b b}(k>0)+2 G_{a b}(k>0) \\
= & d_{a a} n_{a} g\left(k^{2}-1\right) / 3+d_{a a} n_{a} g\left(n_{a}-k\right)(k+1)+d_{b b} n_{b} g\left(k^{2}-1\right) / 3 \\
& +d_{b b} n_{b} g\left(n_{b}-k\right)(k+1)+2 d_{a b} n_{a} n_{b}(k+1) g
\end{aligned}
$$

\subsubsection{Passenger Delay Time $D(k)$}

Delay time at takeoff or landing is exponentially distributed with parameter $\lambda$. Denote total delay time by TDT. The TDT for two travel between two adjacent cities is the sum of two exponential distributions and is an Erlang distribution with parameters $(2, \lambda)$. All carriers choose a common planned delay time $A_{\delta}$ such that $P\left(X \geq A_{\delta}\right)=\delta$.

$k=0$ Network TDT:

Intra Group Travel TDT: Since all cities are directly connected the TDT between cities $\left(O_{i}, D_{i}\right)$ is:

$$
D_{\left(O_{i}, D_{i}\right)}=A_{\delta}
$$

Aggregating over all intra-group O-D city pairs:

$$
D_{i i}(k=0)=\sum_{O_{i}}^{n_{i}} \sum_{D_{i}}^{n_{i}} D_{\left(O_{i}, D_{i}\right)} d_{i i}=A_{\delta} n_{i}\left(n_{i}-1\right) d_{i i}
$$

which yields intra group $A, B$ TDT:

$$
\begin{aligned}
D_{a a}(k=0) & =A_{\delta} n_{a}\left(n_{a}-1\right) d_{a a} \\
D_{b b}(k=0) & =A_{\delta} n_{b}\left(n_{b}-1\right) d_{b b}
\end{aligned}
$$

Inter Group Travel TDT: Since all cities are directly connected, the TDT between cities $\left(O_{i}, D_{j}\right)$ is:

$$
D_{\left(O_{i}, D_{j}\right)}=A_{\delta}
$$


Aggregating over all inter-group O-D city pairs yields:

$$
D_{i j}(k=0)=\sum_{O_{i}}^{n_{i}} \sum_{D_{j}}^{n_{j}} D_{\left(O_{i}, D_{j}\right)} d_{i j}=A_{\delta} n_{i} n_{j} d_{i j}
$$

which yields the TDT for inter-group $A, B$ and $B, A$ travel:

$$
\begin{aligned}
D_{a b}(k=0) & =A_{\delta} n_{i} n_{j} d_{i j} \\
D_{b a}(k=0) & =A_{\delta} n_{i} n_{j} d_{i j}
\end{aligned}
$$

TDT in $k=0$ Network: From the expressions above, the TDT in a $k=0$ network is:

$$
\begin{aligned}
D(k=0) & =D_{a a}(k=0)+D_{b b}(k=0)+2 D_{a b}(k=0) \\
& =A_{\delta} n_{a}\left(n_{a}-1\right) d_{a a}+A_{\delta} n_{b}\left(n_{b}-1\right) d_{b b}+2 A_{\delta} n_{a} n_{b} d_{a b}
\end{aligned}
$$

\section{$k>0$ Network TDT:}

Intra-Group Travel TDT: The TDT for an intra-group intra-tour passenger traveling between cities $\left(O_{i: t}, D_{i: t}\right)$ involves $\left|O_{i: t}-D_{i: t}\right|$. Thus:

$$
D_{\left(O_{i: t}, D_{i: t}\right)}=A_{\delta}\left|O_{i: t}-D_{i: t}\right|
$$

Next consider an intra-group inter-tour passenger traveling between cities $\left(O_{i: t}, D_{i: t^{\prime}}\right)$. Since passengers are exchanged at the center after all $n_{a} / k, n_{b} / k$ after all flights from groups $A, B$ have arrived, the planned delay time at the center is $B_{\delta}$ where $P\left(Y \geq B_{\delta}\right)$ and $Y=\max \left\{n_{a} / k, n_{b} / k\right\}$. The TDT between: cities $O_{i: t}$ and $k_{i: t}$ is $A_{\delta}\left(k_{i: t}-O_{i: t}\right)$ hours; between cities $k_{i: t}$ and the center is $A_{\delta}$ hours; at the center is $B_{\delta}$ hours; between the center and city $k_{i: t^{\prime}}$ is $A_{\delta}$ hours; and between cities $k_{i: t^{\prime}}$ and $D_{i: t^{\prime}}$ is $\left(D_{i: t^{\prime}}\right) A_{\delta}$ hours. Summing these:

$$
D_{\left(O_{i: t}, D_{i: t^{\prime}}\right)}=A_{\delta}\left(k_{i: t}-O_{i: t}\right)+B_{\delta}+A_{\delta}+A_{\alpha}\left(k_{i: t^{\prime}}-D_{i: t^{\prime}}\right)
$$

Since intra tour travel is bi-directional in each of the $n_{i} / k$ sub tours in group $i$ and that there are $\left(n_{i} / k\right)\left(\left(n_{i} / k\right)-1\right)$ inter tours, the total intra group $i$ TDT for all passengers is:

$$
\begin{aligned}
D_{i i}(k>0) & =2 \sum_{O_{i: t}}^{n_{i}} \sum_{D_{i: t}}^{n_{i}} D_{\left(O_{i: t}, D_{i: t}\right)} d_{i i}+\sum_{O_{i: t}}^{n_{i}} \sum_{D_{i: t^{\prime}}}^{n_{i}} D_{\left(O_{i: t}, D_{i: t^{\prime}}\right)} d_{i i} \\
& =2 d_{i i} \frac{n_{i}}{k} \sum_{O_{i: t}}^{k-1} \sum_{O_{i: t}}^{k} D_{\left(O_{i: t}, D_{i: t}\right)}+d_{i i}\left(\frac{n_{i}}{k}-1\right)\left(\frac{n_{i}}{k}\right) \sum_{O_{i: t}}^{k} \sum_{D_{i: t^{\prime}}}^{k} D_{\left(O_{i: t}, D_{i: t^{\prime}}\right)} \\
& =\left\{d_{i i} n_{i} A_{\delta}\left(k^{2}-1\right) / 3\right\}+d_{i i} n_{i} A_{\delta}\left(n_{i}-k\right) k+d_{i i} n_{i}\left(n_{i}-k\right) B_{\delta} \\
& =d_{i i} A_{\alpha}\left\{n_{i}\left(k^{2}-1\right) / 3+n_{i}\left(n_{i}-k\right) k\right\}+d_{i i} B_{\alpha} n_{i}\left(n_{i}-k\right)
\end{aligned}
$$

which yields the TDT for intra group $A, B$ travel:

$$
\begin{aligned}
D_{a a}(k>0) & =d_{a a} A_{\alpha}\left\{n_{a}\left(k^{2}-1\right) / 3+n_{a}\left(n_{a}-k\right) k\right\}+d_{a a} B_{\alpha} n_{a}\left(n_{a}-k\right) \\
D_{b b}(k>0) & =d_{b b} A_{\alpha}\left\{n_{b}\left(k^{2}-1\right) / 3+n_{b}\left(n_{b}-k\right) k\right\}+d_{b b} B_{\alpha} n_{b}\left(n_{b}-k\right)
\end{aligned}
$$

Intra Group Travel TDT: The TDT for travel between cities $\left(O_{i: t}, D_{j: t^{\prime}}\right)$ is:

$$
D_{\left(O_{i: t}, D_{j: t^{\prime}}\right)}=A_{\delta}\left(k_{i: t}-O_{i: t}\right)+B_{\delta}+A_{\delta}+A_{\alpha}\left(k_{i: t^{\prime}}-D_{j: t^{\prime}}\right)
$$


Aggregating over all inter group O-D city pairs yields:

$$
D_{i j}(k>0)=\frac{n_{i}}{k} \frac{n_{j}}{k} \sum_{O_{i}=1}^{n_{i}} \sum_{D_{j}=1}^{n_{j}} D_{\left(O_{i}, D_{j}\right)} d_{i j}=d_{i j} n_{i} n_{j}\left(k A_{\delta}+B_{\delta}\right)
$$

and:

$$
\begin{aligned}
& D_{a b}(k>0)=d_{i j} n_{i} n_{j}\left(k A_{\delta}+B_{\delta}\right) \\
& D_{b a}(k>0)=d_{i j} n_{i} n_{j}\left(k A_{\delta}+B_{\delta}\right)
\end{aligned}
$$

$k>0$ Network TDT: Combining the expressions above yields:

$$
\begin{aligned}
D(k>0)= & D_{a a}(k>0)+D_{b b}(k>0)+2 D_{a b}(k>0) \\
= & \left(d_{a a} A_{\delta}\left\{n_{a}\left(k^{2}-1\right) / 3+n_{a}\left(n_{a}-k\right) k\right\}+d_{a a} B_{\delta} n_{a}\left(n_{a}-k\right)\right) \\
& +\left(d_{b b} A_{\delta}\left\{n_{b}\left(k^{2}-1\right) / 3+n_{b}\left(n_{b}-k\right) k\right\}+d_{b b} B_{\delta} n_{b}\left(n_{b}-k\right)\right) \\
& +2\left(d_{a b} n_{a} n_{b}\left(k A_{\delta}+B_{\delta}\right)\right)
\end{aligned}
$$

\subsection{Passenger Waiting Time $W(k)$}

From any origin city the wait time between flights is $1 / f(k)$ days; thus the average wait time per passenger per day is $f(k) / 2$ or $24 / 2 f(k)=12 / f(k)$ hours.

\section{$k=0$ Network TWT:}

The $k=0$ network has four network routings, with frequencies $f_{a a}(0), f_{b b}(0), f_{a b}(0), f_{b a}(0)$ which yields four wait times:

$$
\begin{aligned}
W(k=0)= & W_{a a}(k=0)+W_{b b}(k=0)+W_{a b}(k=0)+W_{b a}(k=0) \\
= & 12\left\{n_{a}\left(n_{a}-1\right) d_{a a} / f_{a a}(0)+\left(n_{b}\left(n_{b}-1\right) d_{b b}\right) / f_{b b}(0)\right. \\
& \left.+n_{a} n_{b} d_{a b} / f_{a b}(0)+n_{a} n_{b} d_{a b} / f_{b a}(0)\right\}
\end{aligned}
$$

\section{$k>0$ Network TWT:}

The $k>0$ has two network routings, with frequencies $f_{a}(k), f_{b}(k)$ which yield two wait times:

$$
\begin{aligned}
W(k>0)= & W_{a}(k>0)+W_{b}(k>0) \\
= & 12\left\{\left(n_{a}\left(n_{a}-1\right) d_{a a}+n_{a} n_{b} d_{a b}\right) / f_{a}(k)\right. \\
& \left.\left.+\left(n_{b}\left(n_{b}-1\right) d_{b b}\right)+n_{b} n_{a} d_{b a}\right) / f_{b}(k)\right\}
\end{aligned}
$$

\subsection{Total Variable Cost $T V C(k)$}

The total variable cost of operating a flight between cities $i, j$ is equal to total variable cost per seat mile times the total seat miles, where total seat miles is the product of aircraft size $S_{i j}(k)$ times flight frequency $f_{i j}(k)$ times distance (in miles) $\|i-j\|$ :

$$
\begin{aligned}
T V C_{i j}(k) & =S M_{i j}(k) V C(k) \\
& =S_{i j}(k) f_{i j}(k)(\text { Miles } i \rightarrow j)\left\{\alpha+\beta / S_{i j}(k)\right\}
\end{aligned}
$$

Conditional on $k, f(k)$ we derive expressions for $S M(k), S(k)$ below. 


\subsubsection{Aircraft Size $S(k)$}

Aircraft size (seats per plane) is equal to maximum traffic on the route between the O-D city pair $i, j$. Due to the nature of network routings in a $k=0$ network, there are three aircraft sizes corresponding to intra-group $A$, intra-group $B$, and inter-group $A \rightarrow B \equiv B \rightarrow A$ travel, i.e., the same aircraft serves intergroup travel between groups $A$ and $B$; there are however four frequencies. In the $k>0$ network there are two network routings and thus two types of aircrafts..

\section{$k=0$ Network Aircrafts:}

Intra-Group Travel Aircrafts: Maximum demand between any O-D city pair in groups $A, B$ are $d_{a a}, d_{b b}$ respectively. Given $f_{a a}, f_{b b}$ the maximum number of passengers per flight- and therefore the aircraft sizes- are:

$$
\begin{aligned}
S_{a a}(k) & =d_{a a} / f_{a a}(k) \\
S_{b b}(k) & =d_{b b} / f_{b b}(k)
\end{aligned}
$$

Inter-Group Travel Aircraft: A single aircraft type serves inter group travel. Due to symmetrical demand $d_{a b}=d_{b a}$ it is tempting to say that $f_{a b}(0)=f_{b a}(0)$. However this is not true because in the $k=0$ network, the aircraft travels empty along the circumference of group $A$ so that the distance and times between $i, j$ and $j, i$ are not symmetrical which as we show below implies $f_{a b} \neq f_{b a}$. Thus:

$$
S_{a b}(k)=S_{b a}(k)=\max \left\{d_{a b} / f_{a b}(k), d_{b a} / f_{b a}(k)\right\}
$$

\section{$k>0$ Network Aircrafts:}

The $k>0$ network has two aircraft sizes $S_{a}(k), S_{b}(k)$ with frequencies, $f_{a}(k), f_{b}(k)$ respectively. Note that in each sub-tour a flight departs travels from the first city in that sub-tour to the $k$ th city on that sub-tour, from there on to the hub, looping back to the first city on the sub-tour. For group $i$, consider the $q$ th city on a sub-tour of length $k>0$. For $k>1$, when a flight departs from city $q,(k-q) d_{i i}$ intra-group-intra-tour passengers; $\left(n_{i}-k\right) d_{i i}$ intra-group-inter-tour passengers; $n_{j} d_{i j}$ inter group $i$ to group $j$ passengers board the flight. As this flight travels on the sub-tour, at every city $(q-k) d_{i i}$ intra-group-inter-tour passengers dis-embark. Since the number of intra tour passengers aboard the aircraft is a decreasing function of $i$, the maximum number of passengers will be at city $k$, with $N_{i}(k)$ passengers, where:

$$
\begin{aligned}
N_{i}(k) & =\sum_{q=1}^{k}(k-q) d_{i i}+\sum_{q=1}^{k}(n-k) d_{i i}+\sum_{q=1}^{k} n_{j} d_{i j}-\sum_{q=1}^{k}(q-1) d_{i i} \\
& =d_{i i}\left\{k^{2}-k(k+1) / 2+n_{i} k-k^{2}-k(k+1) / 2+k\right\}+n_{j} k d_{i j} \\
& =k\left\{\left(n_{i}-k\right) d_{i i}+n_{i} n_{j} d_{i j}\right\}
\end{aligned}
$$

Now $k=\{0,1, . ., n / 2, n\}$ where $n=\min \left\{n_{a}, n_{b}\right\}$. For a $0<k<n$ network traffic is maximized at the $k$ th stop so that:

$$
S_{i}(0<k<n)=k\left\{\left(n_{i}-k\right) d_{i i}+n_{j} d_{i j}\right\} / f_{i}(k)
$$

Next consider $k=n$ : the total number of intra tour- and therefore intra group- passengers are:

$$
\sum_{q=1}^{k}(k-q) d_{i i}+\sum_{q=1}^{k}(n-k) d_{i i}-\sum_{q=1}^{k}(q-1) d_{i i}=k(n-k) d_{i i}
$$

which implies that intra tour traffic is maximized at the $n / 2$ city and is equal to $d_{i i} n^{2} / 4$ while inter group traffic is $d_{i j} n_{j} n / 2$. At the end of the tour there are $n n_{j} d_{i j}$ passengers. If $d_{i i}>2 n_{j} d_{i j} / n$ then 
$d_{i i} n^{2} / 2+d_{i j} n_{j} n / 2>n n_{j} d_{i j}$. Aircraft size is set to the number of passengers at the $n / 2$ th city so that:

$$
S_{i}(k=n)= \begin{cases}n^{2} d_{i i} / 4+n_{j} d_{i j} n / 2 & \text { if } d_{i i}>2 n_{j} d_{i j} / n \\ n_{i} n_{j} d_{i j} & \text { otherwise }\end{cases}
$$

Aircraft sizes in groups $A, B$ are:

$$
\begin{aligned}
S_{a}(0<k<n) & =k\left\{\left(n_{a}-k\right) d_{a a}+n_{b} d_{a b}\right\} / f_{a}(k) \\
S_{a}(k=n) & = \begin{cases}\left\{n^{2} d_{a a} / 4+n_{b} d_{a b} n / 2\right\} / f_{a}(k) & \text { if } d_{a a}>2 n_{b} d_{a b} / n \\
\left\{n_{a} n_{b} d_{a b}\right\} / f_{a}(k) & \text { otherwise }\end{cases} \\
S_{b}(0<k<n) & =k\left\{\left(n_{b}-k\right) d_{b b}+n_{a} d_{b a}\right\} / f_{b}(k)
\end{aligned}
$$

\subsubsection{Total Seat-Miles $S M(k)$}

Given $k, S(k), f(k)$, derivation of $S M(k)$ requires calculating the total distance (miles) between any O-D city pair.

\section{$k=0$ Network Seat-Miles:}

Intra Group Travel Seat-Miles: In the $k=0$ network, flights operate with and without flights. The total miles traveled with passengers is the sum of the chords for each city in group ito all other $n_{i}-1$ cities; the total miles traveled without passengers is the sum of all arcs connecting all cities in group $i$. Each multiplied by $S(K) f(k)$ yields intra group $i, S M(k)$ :

$$
\begin{aligned}
S M_{i i}(k=0) & =S_{i i}(0) f_{i i}(k) \operatorname{Miles}_{i \rightarrow j} \\
& =S_{i i}(0) f_{i i}(k)\left\{2 n_{i} R_{i} \cot \left(\pi /\left(2 n_{i}\right)\right)+2 \pi R_{i}\right\} \\
& =d_{i i}\left\{2 n_{i} R_{i} \cot \left(\pi /\left(2 n_{i}\right)\right)+2 \pi R_{i}\right\}
\end{aligned}
$$

where the last line is due to $S_{i i}(0)=d_{i i} / f_{i}(k)$. Thus:

$$
\begin{aligned}
S M_{a a}(k=0) & =d_{a a}\left\{2 n_{a} R_{a} \cot \left(\pi /\left(2 n_{a}\right)\right)+2 \pi R_{a}\right\} \\
S M_{b b}(k=0) & =d_{b b}\left\{2 n_{b} R_{b} \cot \left(\pi /\left(2 n_{b}\right)\right)+2 \pi R_{b}\right\}
\end{aligned}
$$

Inter Group Travel Seat-Miles: A single aircraft type serves inter groups $A \rightarrow B$ and $B \rightarrow A$ travel albeit with $f_{a b}(k=0) \neq f_{b a}(k=0)$. Consider first $S M_{a b}(k=0)$ : for each O-D pair, the distance traveled is $R_{a}+R_{b}$ and with $n_{a}$ origin cities and $n_{b}$ destination cities, the total distance traveled for passenger flights is: $n_{a} n_{b}\left(R_{a}+R_{b}\right)$.

Next- recalling that inter group flights in the $k=0$ network originate in group $A-S M_{a b}(k)$ includes the sum of the chords when the flight travels empty along the circumference of group $A$ :

$$
\begin{aligned}
& S M_{a b}(k=0)=S_{a b}(0) f_{a b}(0)\left(n_{a} n_{b}\left(R_{a}+R_{b}\right)+2 \pi R_{a}\right) \\
& S M_{b a}(k=0)=S_{a b}(0) f_{b a}(0) n_{a} n_{b}\left(R_{a}+R_{b}\right)
\end{aligned}
$$

\section{$k>0$ Network:}

In each group flight departs with frequency $f_{i}$ per day from the first city on each sub-tour, travel along the circumference to $k$ th city on the sub-tour, on to the center, and looping back on the same path to first city on the sub-tour, covering a total distance of $2\left\{2 \pi R_{i} / n_{i}(k-1)+R_{i}\right\}$ miles. With $n_{i} / k$ sub-tours the total seat miles in group $i$ is:

$$
\begin{aligned}
S M_{i}(k) & =2\left\{2 \pi R_{i}(k-1) / n_{i}+R_{i}\right\} S_{i}(k) f_{i}(k) n_{i} / k \\
& =2\left\{2 \pi R_{i}(k-1) / n_{i}+R_{i}\right\}\left\{\left(n_{i}-k\right) d_{i i}+n_{j} d_{i j}\right\} n_{i}
\end{aligned}
$$


where the last line follows from $S_{i}(k>0)=k\left\{\left(n_{i}-k\right) d_{i i}+n_{j} d_{i j}\right\} / f_{i}(k)$. Thus:

$$
\begin{aligned}
& S M_{a}(k)=2\left\{2 \pi R_{a}(k-1) / n_{a}+R_{a}\right\}\left\{\left(n_{a}-k\right) d_{a a}+n_{b} d_{a b}\right\} n_{a} \\
& S M_{b}(k)=2\left\{2 \pi R_{b}(k-1) / n_{b}+R_{b}\right\}\left\{\left(n_{b}-k\right) d_{b b}+n_{a} d_{b a}\right\} n_{b}
\end{aligned}
$$

\subsection{Total Fixed Cost}

The total fixed cost between the O-D city pair $i, j$ is equal to total fixed cost per seat day times the total seat days, where total seat days is aircraft size times fleet size (for travel between cities $i, j$ ). The fleet size is the smallest integer greater than $f_{i j} T_{i j}$, denoted $I\left|f_{i j} T_{i j}\right|$, where $T_{i j}$ is the time per trip (days) between $i, j$. If a trip takes $T_{i j}(k)>1 / f_{i k}(k)$ then carriers will need more than one aircraft; fleet size will be $I\left|f_{i j} T_{i j}\right|$. The derivation of:

$$
T F C_{i j}(k)=\gamma S_{i j}(k) I\left|f(k) T_{i j}\right|=\gamma S D_{i j}(k)
$$

requires calculating time per trip.

\subsubsection{Total Available Seat Days \& Trip Times}

\section{$k=0$ Network:}

Intra Group Travel Seat-Days: The time needed to complete a trip per flight is the flight plus takeoff/landing time plus planned delay time ${ }^{14}$. Using earlier expressions for distance and $S(k)$ from above, intra group $i$ travel time is:

$$
\begin{aligned}
T_{i i}(k=0) & =\operatorname{Miles}_{i \rightarrow j} / v+n_{i}\left(n_{i}-1\right)\left(g+A_{\delta}\right) \\
& =\left\{2 n_{i} R_{i} \cot \left(\pi / 2 n_{i}\right)+2 \pi R_{i}\right\} / v+n_{i}\left(n_{i}-1\right)\left(g+A_{\delta}\right)
\end{aligned}
$$

Assuming $I|f(k) T(k)|$ is a large number so that $I|f(k) T(k)| \approx f(k) T(k)$ and recalling $S(k)=$ $d / f(k)$ :

$$
\begin{aligned}
S D_{a a}(k=0) & =S_{a a}(0) I\left|f_{a a}(0) T_{a a}(0)\right|=d_{a a} T_{a a}(0) \\
S D_{b b}(k=0) & =S_{b b}(0) I\left|f_{b b}(0) T_{b b}(0)\right|=d_{b b} T_{a a}(0)
\end{aligned}
$$

Inter Group Travel Seat-Days: Recalling the aircraft travels empty along the circumference of group $A$ :

$$
\begin{aligned}
T_{a b}(k=0) & =\text { Miles } A / v+n_{a}\left(n_{a}-1\right)\left(g+A_{\delta}\right) \\
& =\left\{n_{a} n_{b}\left(R_{a}+R_{b}\right)+2 \pi R_{a}\right\} / v+n_{a}\left(n_{a}-1\right)\left(g+A_{\delta}\right) \\
T_{b a}(k=0) & =\text { Miles } B / v+n_{b}\left(n_{b}-1\right)\left(g+A_{\delta}\right) \\
& =\left\{n_{a} n_{b}\left(R_{a}+R_{b}\right)\right\} / v+n_{a} n_{b}\left(g+A_{\delta}\right)
\end{aligned}
$$

Since the same aircraft serves inter-group travel $A \rightarrow B$ and $B \rightarrow A$ with size:

$$
S_{a \rightarrow b}(0)=\max \left\{d_{a b} / f_{a b}(k=0), d_{b a} / f_{b a}(k=0)\right\}
$$

the total number of seats for inter group travel is:

$$
\begin{aligned}
S D_{a b}(k=0) & =S_{a \rightarrow b}(0) I\left|f_{a a}(0) T_{a a}(0)\right| \\
S D_{b b}(k=0) & =S_{a \rightarrow b}(0) I\left|f_{b b}(0) T_{b b}(0)\right|
\end{aligned}
$$

\footnotetext{
${ }^{14}$ Note this is not the same as passenger flight, takeoff/landing, and planned delay time because the aircraft travels empty for some portions of the trip
} 
$k>0$ Network:

Consider the path of a fight in a sub tour of length $k$ in group $i$ : depart from the first city in the sub tour, travel along the circumference stopping at each city until the $k$ th city on that sub-tour, traveling along the radius $R_{i}$ to the center and looping back on the same path to the first city in the sub-tour. The total travel time for this path is total flight time plus total takeoff/landing time plus total planned delay time.

Total flight time is total distance divided by velocity $2\left\{(k-1)\left(2 \pi R_{i}\right) / n_{i}+R_{i}\right\} / v$. For total takeoff/landing time consider the itinerary of a flight: from the first to the $k$ th cities of the sub tour there are $(k-2)$ stops each of which take $g$ hours in takeoff and landing; takeoff from the first city and landing at the $k$ th city each take $g / 2$ hours; takeoff from the $k$ th city to and landing at the center totals $g$ hours. Thus, takeoff/landing time in one direction is $(k-2) g+g+g=k g$ so that the total takeoff/landing time for the round trip is $2 \mathrm{~kg}$.. Total planned delay time is $(2 k-1) A_{\delta}+B_{\delta}$ hours. Summing the TFT, TLT and TDT, the total trip time (days) is:

$$
T_{i}(k)=2\left\{(k-1) 2 \pi R_{i} / n_{i}+R_{i}\right\} / v+2 k g+2(k-1) A_{\alpha}+B_{\alpha}
$$

hours. The number of (daily) dispatches is $I\left[f_{i}(k) T_{i}(k)\right]$. Thus the total available seat days on a sub-tour is $S_{i}(k) I\left[f_{i}(k) T_{i}(k)\right]$ which implies that the total available seat days in group $i$, assuming $I\left[f_{i}(k) T_{i}(k)\right] \approx f_{i}(k) T_{i}(k)$, is:

$$
S D_{i}(k)=S_{i}(k) I\left[f_{i}(k) T_{i}(k)\right] n_{i} / k \approx S_{i}(k) f_{i}(k) T_{i}(k) n_{i} / k
$$

Substituting for aircraft size and recalling that $S(0<k<n) \neq S(k=n)$ :

$$
\begin{aligned}
S D_{i}(0<k<n) & =\left\{\left(n_{i}-k\right) d_{i i}+n_{j} d_{i j}\right\} n_{i} T_{i}(k) \\
S D_{i}(k=n) & = \begin{cases}\left\{n^{2} d_{i i} / 4+n_{j} d_{i j} n / 2\right\} n_{i} T_{i}(k) / k & \text { if } d_{i i}>2 n_{j} d_{i j} / n \\
\left\{n_{i} n_{j} d_{i j}\right\} T_{i}(k) n_{i} T_{i}(k) / k & \text { otherwise }\end{cases}
\end{aligned}
$$

Thus:

$$
\begin{aligned}
& S D_{a}(0<k<n)=\left\{\left(n_{a}-k\right) d_{a a}+n_{b} d_{a b}\right\} n_{a} T_{a}(k) \\
& S D_{a}(k=n)= \begin{cases}\left\{n^{2} d_{a a} / 4+n_{b} d_{a b} n / 2\right\} n_{a} T_{a}(k) / k & \text { if } d_{a a}>2 n_{b} d_{a b} / n \\
\left\{n_{a} n_{b} d_{a b}\right\} n_{a} T_{a}(k) / k & \text { otherwise }\end{cases} \\
& S D_{b}(0<k<n)=\left\{\left(n_{b}-k\right) d_{b b}+n_{a} d_{b a}\right\} n_{b} T_{b}(k) \\
& S D_{b}(k=n)= \begin{cases}\left\{n^{2} d_{b b} / 4+n_{a} d_{b a} n / 2\right\} n_{b} T_{b}(k) / k & \text { if } d_{b b}>2 n_{a} d_{b a} / n \\
\left\{n_{a} n_{b} d_{b a}\right\} n_{b} T_{b}(k) / k & \text { otherwise }\end{cases}
\end{aligned}
$$

\subsection{Optimal Flight Frequencies}

Given $k, S(k)$, carriers choose frequencies to minimize the objective $C(k)$ in Equation 8, where the passenger waiting times cost and carriers cost are functions of $f(k)$. Thus, optimal frequencies minimize frequency related cost:

$$
F R C(k, f(k))=W(k, f(k))+T V C(k, f(k))+T F C(k, f(k))+O(k, f(k))
$$

$k=0$ Network:

Intra Group Travel Frequencies: The frequency related cost for intra group $i$ travel is:

$$
\begin{aligned}
F R C_{i i}(0, f(0))= & W_{i i}(0, f(0))+T V C_{i i}(0, f(0))+T F C_{i i}(0, f(0)) \\
= & 12 w\left\{n_{i}\left(n_{i}-1\right) d_{i i} / f_{i i}(0)\right\}+S M_{i i}(0)\left\{\alpha+\beta / S_{i i}(0)\right\}+S D_{i i}(0, f(0)) \gamma \\
= & 12 w\left\{n_{i}\left(n_{i}-1\right) d_{i i} / f_{i i}(0)\right\}+S M_{i i}(0)\left\{\alpha+\beta f_{i i}(0) / N_{i i}(0)\right\} \\
& +\left(N_{i i}(0) / f_{i i}(0)\right) I\left|f_{i i}(0) T_{i i}(0)\right| \gamma \\
= & 12 w\left\{n_{i}\left(n_{i}-1\right) d_{i i} / f_{i i}(0)\right\}+S M_{i i}(k)\left\{\alpha+\beta f_{i i}(0) / N_{i i}(0)\right\}+N_{i i}(0) T_{i i}(0) \gamma
\end{aligned}
$$


where we've assumed $I\left|f_{i i}(0) T_{i i}(0)\right| \approx f_{i i}(0) T_{i i}(0) . S M_{i i}(0)$ is independent of $f_{i i}(0)$ since:

$$
\begin{aligned}
S M_{i i}(0) & =S_{i i}(0) f_{i i}(0) \operatorname{Miles}_{i} \\
& =\left(N_{i i}(0) / f_{i i}(0)\right) f_{i i}(0) \operatorname{Miles}_{i} \\
& =N_{i i}(0) \operatorname{Miles}_{i}
\end{aligned}
$$

Thus: $F R C_{i i}(0, f(0))=1 / f_{i i}(0)\left\{12 w n_{i}\left(n_{i}-1\right) d_{i i}\right\}+\beta S M_{i i}(0) f_{i i}(0) / N_{i i}(0)$. Differentiating with respect to $f_{i i}(0)$ yields:

$$
f_{i i}(0)=\sqrt{\frac{12 w n_{i}\left(n_{i}-1\right) d_{i i}}{\beta S M_{i i}(0) / N_{i i}(0)}}
$$

Thus:

$$
\begin{aligned}
f_{a a}(0) & =\sqrt{\frac{12 w n_{a}\left(n_{a}-1\right) d_{a a}}{S M_{a a}(k) \beta / N_{a a}(0)}} \\
f_{b b}(0) & =\sqrt{\frac{12 w n_{b}\left(n_{b}-1\right) d_{b b}}{S M_{b b}(k) \beta / N_{b b}(0)}}
\end{aligned}
$$

Inter Group Travel Frequencies: A single aircraft serves inter group travel, albeit with $f_{a b}(0) \neq$ $f_{b a}(0)$. To compute frequencies we need the aircraft size. However, recall from Equation 9 that $S_{a \rightarrow b}(0)=S_{b \rightarrow a}(0)=\max \left\{d_{a b} / f_{a b}(0), d_{b a} / f_{b a}(0)\right\}$. Therefore, to compute optimal frequencies, first assume $1 / f_{a b}(0)>1 / f_{b a}(0)$ so that $S_{a \rightarrow b}(0)=d_{a b} / f_{a b}(0)$ followed by the assumption $1 / f_{a b}(0)<1 / / f_{b a}(0)$ so that $S_{a \rightarrow b}(0)=d_{a b} / f_{b a}(0)$. Second, compare the frequency related costs for each pair of frequencies, from which the optimal frequencies are:

$$
f_{a b}(0), f_{b a}(0)=\min _{f_{a b}, f_{b a}}\left\{F R C_{a b}\left(k: 1 / f_{a b}(0)>1 / f_{b a}(0)\right), F R C_{a b}\left(k: 1 / f_{a b}(0)<1 / f_{b a}(0)\right)\right\}
$$

This yields:

$$
S_{a b}(0)= \begin{cases}d_{a b} \max \left\{1 / f_{a b}(0), 1 / f_{b a}(0)\right\}=d_{a b} / f_{a b}(0) & \text { if } 1 / f_{a b}(0)>1 / f_{b a}(0) \\ d_{a b} \max \left\{1 / f_{a b}(0), 1 / f_{b a}(0)\right\}=d_{a b} / f_{b a}(0) & \text { otherwise }\end{cases}
$$

Denote $\max \left\{1 / f_{a b}(0), 1 / f_{b a}(0)\right\}=1 / f_{a-b}(0) .$. Now, $F R C_{a-b}$ is:

$$
\begin{aligned}
F R C_{a-b}(0, f(0))= & W_{a b}(0, f(0))+T V C_{a b}(0, f(0))+T F C_{a b}(0, f(0)) \\
& +W_{b a}(0, f(0))+T V C_{b a}(0, f(0))+T F C_{b a}(0, f(0)) \\
= & 12 w n_{a} n_{b} d_{a b} / f_{a b}(0)+S M_{a b}(0)\left\{\alpha+\beta / S_{a-b}(0)\right\}+\gamma S D_{a b}(0, f(0)) \\
& +12 w n_{b} n_{a} d_{b a} / f_{b a}(0)+S M_{b a}(0)\left\{\alpha+\beta / S_{a-b}(0)\right\}+\gamma S D_{b a}(0, f(0)) \\
= & 12 w n_{a} n_{b} d_{a b} / f_{a b}(0) \\
& +f_{a b}(0)\left\{\alpha+\beta / S_{a-b}(0)\right\} \operatorname{Miles}_{A \rightarrow B} N_{a b}(0) / f_{a-b}(0) \\
& +\gamma I\left|f_{a b}(0) T_{a b}(0)\right| N_{a b}(0) / f_{a-b}(0)+12 w n_{b} n_{a} d_{b a} / f_{b a}(0) \\
& +f_{b a}(0)\left\{\alpha+\beta / S_{a-b}(0)\right\} \operatorname{Miles}_{A \rightarrow B} N_{b a}(0) / f_{a-b} \\
& +\gamma I\left|f_{a b}(0) T_{a b}(0)\right| N_{a b} / f_{a-b}(0)
\end{aligned}
$$

Here $S M_{a b}, S M_{b a}$ are not (necessarily) independent of flight frequencies so that an analytical solution is not possible. Instead, in the analysis of the model below, we use numerical methods to derive the optimal flight frequencies for inter group travel in the $k=0$ network.. 
$k>0$ Network:

The frequency related cost for travel originating in group $i$ is:

$$
\begin{aligned}
F R C_{i}(k, f(k))= & W_{i}(k, f(k))+T V C_{i}(k, f(k))+T F C_{i}(k, f(k)) \\
= & 12 w\left(n_{i}\left(n_{i}-1\right) d_{i i}+n_{i} n_{j} d_{i j}\right) / f_{i}(k) \\
& +S M_{i}\left\{\alpha+\beta / S_{i}(k)\right\}+\gamma S D_{i}(k) \\
= & 12 w\left(n_{i}\left(n_{i}-1\right) d_{i i}+n_{i} n_{j} d_{i j}\right) / f_{i}(k) \\
& +S M_{i}\left\{\alpha+\beta f_{i}(k) / N_{i}(k)\right\}+\gamma S D_{i}(k)
\end{aligned}
$$

where the last line follows from the fact that aircraft size is maximum traffic, denoted $N_{i}(k) / f_{i}(k)$. $F R C_{i}(k, f(k))$ can be simplified further by noting that $S M_{i}(k)$ is independent of $f_{i}(k)$ :

$$
\begin{aligned}
S M_{i i}(k) & =S_{i i}(k) f_{i i}(k) \operatorname{Miles}_{i} \\
& =\left(N_{i i}(k) / f_{i i}(k)\right) f_{i i}(k) \operatorname{Miles}_{i} \\
& =N_{i i}(k) \operatorname{Miles}_{i}
\end{aligned}
$$

$S D_{i}(k)$ is independent of $f_{i}(k)$ because $S D_{i}(k) \approx S_{i}(k) f_{i}(k) T_{i}(k)=N_{i}(k) T_{i}(k)$. Collecting frequency related terms $F R C_{i}(k, f(k))$ becomes:

$$
F R C C_{i}(k, f(k))=\left\{12 w\left(n_{i}\left(n_{i}-1\right) d_{i i}+n_{i} n_{j} d_{i j}\right)+\beta S M_{i}(k) f_{i}(k) / N_{i}\right\} / f_{i}(k)
$$

The first order condition yields:

$$
f_{i}(k>0)=\sqrt{\frac{12 w\left(n_{i}\left(n_{i}-1\right) d_{i i}+n_{i} n_{j} d_{i j}\right)}{\beta S M_{i}(k) / N_{i}}}
$$

from which:

$$
\begin{aligned}
& f_{a}(k>0)=\sqrt{\frac{12 w\left(n_{a}\left(n_{a}-1\right) d_{a a}+n_{a} n_{b} d_{a b}\right)}{\beta S M_{a}(k) / N_{a}}} \\
& f_{b}(k>0)=\sqrt{\frac{12 w\left(n_{b}\left(n_{a}-1\right) d_{b b}+n_{b} n_{a} d_{b a}\right)}{\beta S M_{b}(k) / N_{b}}}
\end{aligned}
$$

\section{Analysis: Optimal Networks \& Post-Deregulation U.S. Airline Industry}

In this section we first demonstrate that LN (1998) result that any network structure can be optimal also holds in our two group model; and second, we explain and analyze the evolution of network structure and design over the past three decades of the deregulated U.S. airline industry. ${ }^{15}$

\subsection{Optimal Network Structure}

\subsubsection{LN (1998) on Optimal Networks}

LN (1998) show that any network structure can be optimal: the precise network structure is a complicated function of demand, distance, number of cities, passenger cost per hour of traveling

\footnotetext{
${ }^{15}$ Other results from this model are in a companion paper: "Network Structure and Design in the Post-Deregulation U.S. Airline Industry: an Argument for Re-Regulation" available upon request.
} 
and waiting between flights, delays at takeoff/landing and hubs, aircraft size and velocity, variable cost per seat mile economies of scale in aircraft size and fixed cost per seat day. Instead of a complete investigation of the impact of these parameters on network structure and design, we focus here on a few key economically interesting factors. In each case below, LN's results extend to our two group model.

Ceteris paribus, as demand increases the network structure tends to be a P2P; conversely, as demand weakens the optimal network structure tends first to a HS and then sub-tour network. To see the intuition consider travel between the two continental U.S. coasts. Suppose aircraft size is exogenously given: if there is weak demand between Boston-LA and New York-LA, it is cheaper for carriers to fly all West Coast bound passengers from Boston and New York first to a hub from where all LA bound passengers are placed on a single flight. The hub concentrates traffic from all origins on the East Coast into direct flights from the hub to all destination cities on the West Coast. Conversely, if demand between Boston-LA and New York-LA increases, it becomes efficient to operate direct flights- there is enough demand to justify the fixed cost of the aircraft.

Similarly, as the distance between cities increases, sub-tour and tour networks become optimal. This is because the variable costs of a $\mathrm{P} 2 \mathrm{P}$ network rise dramatically as the distance increases even if aircraft utilization is high due to strong demand. Conversely, as the distance becomes smaller, a P2P network becomes optimal. Finally, ceteris paribus, if the network consists of a small number of (exogenously given) cities, the optimal network tends to be a sub-tour or tour. But as the number of cities increases, the optimal network structure becomes a HS. This is because passengers dislike travel and wait times. If carriers operated a sub-tour or tour network over a large number of cities, the lower variable cost is outweighed by increased passengers' cost of travel.

These factors point to some key aspects of so called LCCs: their success is due to cherry picking routes and serving a 'patient' segment of the travel market. That is, LCCs deliberately operate flights over a small number of cities with low average distance and high demand: for example, Heskett (2003) estimates that Southwest serves the following percentages of potential routes: 100400 miles, 55\%; 400-800 miles, 27\%; 800-1,200 miles: 20\%; > 1,200 miles, 8\%. At the same time, if LCCs' passengers have a low cost of traveling, the LCCs will operate sub-torur networks. Conversely, it implies that as passengers cost of travel increases, it would be optimal to shift away from sub-tour networks towards a P2P or HS network. This further suggests that carriers can 'tailor' network structure structure to cities. For example, passengers from and to Las Vegas may place a high premium on getting there quickly and for low wait times between flights. Hence, it would behoove airlines to connect Las Vegas with other 'passenger travel and wait premium' cities by a HS or direct network while possibly connecting other cities by other types of network structures.

In our opinion, these factors suggest that following deregulation, given the large number of cities spread over a great distance, it was optimal for legacy carriers to setup HS networks; of course, under a different set of parameters, another network structure may have emerged. For example, observe the prevalence of $\mathrm{P} 2 \mathrm{P}$ networks in $\mathrm{EU}$ which is unsurprising given its smaller radius compared to the U.S. (see Brueckner, Goebel and Niskanen (1997) for an analysis of network structures in the EU.).

\subsection{Post-Deregulation Network Structure and Design: Explanation and Analysis}

We assume that legacy carriers optimally setup HS networks after regulation ended in 1978. Our investigation of network structure evolution and design and its impact on social welfare is through a four stage game. In stage 1 legacy carriers setup HS networks ${ }^{16}$. Observe that we do not impose

\footnotetext{
${ }^{16}$ This is a testable assumption, which we pursue in a later paper: 1978 data on number of cities, average distance, demand, and aircraft characteristics can be inputted into the model to see if the optimal network is a HS.
} 
restrictions on the number of carriers in stage 1. For any given number of incumbent carriers, entrants will enter the market and setup HS network so long as their share of profits, however determined, is greater than the fixed cost. Once the potential profits are smaller than the fixed cost, we assume potential entrants look for 'subsets' of markets to enter.

For tractability we assume that in stage 2, entrants will either enter the intra-group $A$ or intragroup $B$ travel markets: entrants first choose the optimal network structure and design in each market (by minimizing the passengers plus airlines costs) and choose the more profitable market.

Legacy carriers respond to the entrants in the short and long run. The short run is modeled in stage 3: legacy carriers alter the 'variable input' frequency- holding fixed inputs network structure and aircrafts constant- which leads to a change in prices. The long run is modeled in stage 4: legacy carriers alter all inputs including network structure.

The parameters of the model are chosen to 'calibrate' the model with the fact that legacy carriers operated HS networks after regulation ended and continue doing so: $n_{a}=4, n_{b}=8, R_{a}=$ $200, R_{b}=600, d_{a a}=15, d_{b b}=d_{a b}=d_{b a}=10, B_{a a}=B_{b b}=B_{a b}=B_{b a}=800, \bar{U}=10, w=\$ 15, t=$ $\$ 10, g=0.3, v=50, \lambda=2, \delta=0.1$.

Table 1: Network Structure and Design in the Four-Stage Game

\begin{tabular}{lccccccc}
\hline \hline & \multicolumn{2}{c}{ Stage 1 } & Stage 2 & \multicolumn{2}{c}{ Stage 3 } & \multicolumn{2}{c}{ Stage 4 } \\
& Legacy & Entrant & \multicolumn{2}{c}{ Legacy: Short run } & \multicolumn{2}{c}{ Legacy: Long Run } \\
& $A$ & $B$ & $B$ & $A$ & $B$ & $A$ & $B$ \\
\hline$k$ (network) & 1 & 1 & 4 & 1 & 1 & 1 & 1 \\
$f(k)$ (daily) & 0.40 & 0.21 & 0.19 & 0.40 & 0.13 & 0.40 & 0.13 \\
$S(k)$ (seats) & 911 & 1796 & 208 & 911 & 1738 & 911 & 2444 \\
Fleet (planes) & 24 & 56 & 110 & 24 & 56 & 24 & 32 \\
\hline \hline
\end{tabular}

\subsubsection{Optimal Network Structure and Design}

Table 1 summarizes the optimal network and design in the 4 stage game. By assumption, in stage 1 legacy carriers choose a HS network $k=1$ over groups $A$ and $B$. Group $B$ has lower flight frequencies, longer wait times between flights, larger aircraft, and a larger fleet.

In stage 2 , entrants optimally choose group $B$ and operate a sub-tour $k=4$ network. That entrants have chosen a sub-tour network given legacy carriers' HS network is, of course, not a general result but with empirical support it debunks the perception that so called LCCs operate P2P networks. For empirical support we use Berry et al (2004) measure of network structure: consider the relationship between the number of 'nodes' in a network and the number of links from each node to other nodes:

$$
\text { Number of Nodes }=a \text { Number of Links }{ }^{b}
$$

In a P2P network, all nodes have many links, while in a HS network some nodes have many links while most links have few links. Hence, in a P2P network we'd expect $b>0$ while for a HS network $b<0$; the parameter $a$ can be interpreted as a measure of network size. Hussain (2006) estimates $a, b$ for every node and its links for various carriers for 1990, 1995, 2000, and 2006, the results of which are in Table 2. All legacy carriers operate HS networks while for 1990, 1995 and 2000, LCCs operated non-HS networks. In particular, note that Southwest arguably had a P2P network before 1990 but has since- see $b$ in 1995 and 2000- moved away from that structure.

Comparing group $B$ across stages 1 and 2, observe that entrants have a larger fleet consisting smaller aircraft operating with lower frequency. Comparing stage 2 with stage 3 LCCs operate 
Table 2: Network Structure Regression Results

\begin{tabular}{lcccccccc}
\hline \hline & \multicolumn{2}{c}{1990} & \multicolumn{2}{c}{1995} & \multicolumn{2}{c}{2000} \\
& $a$ & $b$ & $a$ & $b$ & $a$ & $b$ & $a$ & $b$ \\
\hline \hline Legacy Carriers & & & & & & & & \\
Northwest & 16.44 & -0.71 & 9.63 & -0.49 & 12.17 & -0.57 & 18.02 & -0.70 \\
American & 12.88 & -0.54 & 6.81 & -0.37 & 14.03 & -0.67 & 12.20 & -0.70 \\
US Air & 9.03 & -0.47 & 19.21 & -0.75 & 6.95 & -0.41 & 7.86 & -0.55 \\
American West & 8.16 & -0.59 & 14.85 & -0.79 & 5.79 & -0.37 & 8.17 & -0.59 \\
Delta & 24.61 & -0.79 & 15.99 & -0.65 & 11.61 & -0.52 & 22.70 & -0.84 \\
Continental & 12.93 & -0.59 & 9.07 & -0.58 & 14.06 & -0.68 & 23.10 & -0.86 \\
United & 14.46 & -0.61 & 13.21 & -0.62 & 14.68 & -0.66 & 19.56 & -0.78 \\
\hline \hline 'Low Cost' Carriers & & & & & & & & \\
Southwest & 0.65 & 0.45 & 1.32 & 0.07 & 1.4 & 0.04 & 2.27 & -0.08 \\
Jet Blue & & & & & 1.18 & 0.11 & 8.28 & -0.82 \\
\hline \hline
\end{tabular}

Source: DOT. Data on nodes and routes unavailable before 1990. Jet Blue did not exist in 1995.

flights with higher frequency than legacy carriers which is consistent with the data. LCCs higher frequencies result in shorter wait times between flights which suggests ceteris paribus that LCCs may not necessarily charge lower prices than legacy carriers. In fact, we show this to be the case for some routes.

In stage 4 when legacy carriers vary all 'inputs' by re-optimizing network structure and design the optimal network structure continues to be a HS- consistent with the data in Table 2- with no change in group $A$ network design, and lower frequencies, smaller fleet and larger aircraft in group $B$.

\subsubsection{Prices}

From equation 7 the price for travel between an O-D city pair $i, j$ is:

$$
p_{i j}(k)=B_{i j}-t T_{i j}(k)-w W_{i j}(k)-\Delta_{i j}-\bar{U}_{i j}
$$

For every O-D city pair, we calculate travel and wait times and therefore the price. Recall travel time is the distance divided by velocity of the itinerary connecting cities $i, j$ and wait time is a function of flight frequencies. For intra-group travel, waiting time between flights is a function of group frequency, whereas for inter-group travel wait time is a function of both groups' frequencies. This implies that in stage 3 when legacy carriers respond to LCCs entry into group $B$ there is no change in group $A$ prices whereas there will be a change in group $B$ and inter-group $A, B$ and $B, A$ prices $^{17}$.

Tables 3,4 and 5 contain intra-group $A$, inter-group $A \rightarrow B=B \rightarrow A$ and intra group $B$ travel prices respectively. Entry does not affect intra-group $A$ prices since it does not affect legacy carriers prices for intra-group $A$ travel. But because legacy carriers adjust group $B$ frequencies, prices for all other travel markets change; that is, there is a "ripple" effect from entry leading to lower prices in markets without direct competition which might be charitably interpreted as the salubrious effect increased rivalry or sinisterly interpreted as entry deterrence pricing.

\footnotetext{
${ }^{17}$ If passenger's waiting cost stems from waiting time at the origin only then group $A \rightarrow B$ prices will not equal group $B \rightarrow A$ prices and LCCs will impact prices for group $B \rightarrow A$ but not group $A \rightarrow B$ travel.
} 
Table 3: Intra-Group $A$ Travel Prices

\begin{tabular}{ccccc}
\hline \hline City & $1_{a}$ & $2_{a}$ & $3_{a}$ & $4_{a}$ \\
\hline \hline \multicolumn{5}{c}{ Stage 1: Legacy Carrier Prices } \\
$1_{a}$ & $*$ & 7.9930 & 7.9930 & 7.9930 \\
$2_{a}$ & 7.9930 & $*$ & 7.9930 & 7.9930 \\
$3_{a}$ & 7.9930 & 7.9930 & $*$ & 7.9930 \\
$4_{a}$ & 7.9930 & 7.9930 & 7.9930 & $*$ \\
\hline \hline \multicolumn{5}{c}{ Stage 2: LCC Prices } \\
\hline \hline \multicolumn{5}{c}{ Not Applicable } \\
$1_{a}$ & $*$ & 7.9930 & 7.9930 & 7.9930 \\
$2_{a}$ & 7.9930 & $*$ & 7.9930 & 7.9930 \\
$3_{a}$ & 7.9930 & 7.9930 & $*$ & 7.9930 \\
$4_{a}$ & 7.9930 & 7.9930 & 7.9930 & $*$ \\
\hline \hline \multicolumn{5}{c}{ Stage 4: Legacy Carrier Prices } \\
$1_{a}$ & $*$ & 7.9930 & 7.9930 & 7.9930 \\
$2_{a}$ & 7.9930 & $*$ & 7.9930 & 7.9930 \\
$3_{a}$ & 7.9930 & 7.9930 & $*$ & 7.9930 \\
$4_{a}$ & 7.9930 & 7.9930 & 7.9930 & $*$ \\
\hline \hline
\end{tabular}

In fact, it's the consequence of optimal network structure and design: the change in inter-group $A \rightarrow B$ travel prices occurs because even though travel originates from group $A$ - where frequencies remain unchanged-- passengers are exchanged at the center and put on group $B$ flights to their destinations.

A comparison of stage 2 and stage 3 prices shows that the entrants may charge higher prices on some routes and charge lower prices on other routes. Thus, competition does not always lower prices and empirical studies using average fares may incorrectly conclude that all prices have fallen when in fact some prices have fallen while others have risen. One of the reasons for higher prices is due to the entrants' higher flight frequency which leads to shorter wait times between flights for which passengers are charged a higher price. Another reason is that the entrant transports passengers faster with a sub-tour network than a HS network. For example, passengers traveling between adjacent cities on the sub-tour are on direct flights whereas in the HS network they go through a hub. Since the direct flight between adjacent cities travels a shorter distance, travel times are quicker and consequently passengers are charged a higher price. 
Table 4: Inter-Group $A \rightarrow B$ and $B \rightarrow A$ Prices

\begin{tabular}{ccccccccc}
\hline \hline City & $1_{b}$ & $2_{b}$ & $3_{b}$ & $4_{b}$ & $5_{b}$ & $6_{b}$ & $7_{b}$ & $8_{b}$ \\
\hline \hline \multicolumn{7}{c}{ Stage 1: Legacy Carriers Prices } \\
$1_{a}$ & 7.9839 & 7.9839 & 7.9839 & 7.9839 & 7.9839 & 7.9839 & 7.9839 & 7.9839 \\
$2_{a}$ & 7.9839 & 7.9839 & 7.9839 & 7.9839 & 7.9839 & 7.9839 & 7.9839 & 7.9839 \\
$3_{a}$ & 7.9839 & 7.9839 & 7.9839 & 7.9839 & 7.9839 & 7.9839 & 7.9839 & 7.9839 \\
$4_{a}$ & 7.9839 & 7.9839 & 7.9839 & 7.9839 & 7.9839 & 7.9839 & 7.9839 & 7.9839 \\
\hline \hline \multicolumn{7}{c}{ Stage 2: LCC Prices } \\
\hline \hline \multicolumn{7}{c}{ Not Applicable } \\
$1_{a}$ & 7.9793 & 7.9793 & 7.9793 & 7.9793 & 7.9793 & 7.9793 & 7.9793 & 7.9793 \\
$2_{a}$ & 7.9793 & 7.9793 & 7.9793 & 7.9793 & 7.9793 & 7.9793 & 7.9793 & 7.9793 \\
$3_{a}$ & 7.9793 & 7.9793 & 7.9793 & 7.9793 & 7.9793 & 7.9793 & 7.9793 & 7.9793 \\
$4_{a}$ & 7.9793 & 7.9793 & 7.9793 & 7.9793 & 7.9793 & 7.9793 & 7.9793 & 7.9793 \\
\hline \hline \multicolumn{8}{c}{ Stage 4: Legacy Carriers Prices } \\
$1_{a}$ & 7.9784 & 7.9784 & 7.9784 & 7.9784 & 7.9784 & 7.9784 & 7.9784 & 7.9784 \\
$2_{a}$ & 7.9784 & 7.9784 & 7.9784 & 7.9784 & 7.9784 & 7.9784 & 7.9784 & 7.9784 \\
$3_{a}$ & 7.9784 & 7.9784 & 7.9784 & 7.9784 & 7.9784 & 7.9784 & 7.9784 & 7.9784 \\
$4_{a}$ & 7.9784 & 7.9784 & 7.9784 & 7.9784 & 7.9784 & 7.9784 & 7.9784 & 7.9784 \\
\hline \hline
\end{tabular}


Table 5: Intra-Group $B$ Travel Prices

\begin{tabular}{|c|c|c|c|c|c|c|c|c|}
\hline$\overline{\text { City }}$ & $1_{b}$ & $22_{b}$ & $3_{b}$ & $4_{b}$ & $5_{b}$ & $6_{b}$ & $7_{b}$ & $\overline{88_{b}}$ \\
\hline \multicolumn{9}{|c|}{ "Stage 1: Legacy Carriers Prices } \\
\hline $1_{b}$ & $*$ & 7.9876 & 7.9876 & 7.9876 & 7.9876 & 7.9876 & 7.9876 & 7.9876 \\
\hline $2_{b}$ & 7.9876 & * & 7.9876 & 7.9876 & 7.9876 & 7.9876 & 7.9876 & 7.9876 \\
\hline $3_{b}$ & 7.9876 & 7.9876 & $*$ & 7.9876 & 7.9876 & 7.9876 & 7.9876 & 7.9876 \\
\hline $4_{b}$ & 7.9876 & 7.9876 & 7.9876 & $*$ & 7.9876 & 7.9876 & 7.9876 & 7.9876 \\
\hline $5_{b}$ & 7.9876 & 7.9876 & 7.9876 & 7.9876 & $*$ & 7.9876 & 7.9876 & 7.9876 \\
\hline $6_{b}$ & 7.9876 & 7.9876 & 7.9876 & 7.9876 & 7.9876 & $*$ & 7.9876 & 7.9876 \\
\hline $7_{b}$ & 7.9876 & 7.9876 & 7.9876 & 7.9876 & 7.9876 & 7.9876 & $*$ & 7.9876 \\
\hline $8_{b}$ & 7.9876 & 7.9876 & 7.9876 & 7.9876 & 7.9876 & 7.9876 & 7.9876 & $*$ \\
\hline \multicolumn{9}{|c|}{ Stage 2: LCC Prices } \\
\hline \multicolumn{9}{|c|}{ Intra-Tour Prices } \\
\hline $1_{b}$ & $*$ & 7.9888 & 7.9870 & 7.9853 & & & & \\
\hline $2_{b}$ & 7.9888 & $*$ & 7.9888 & 7.9870 & & & & \\
\hline $3_{b}$ & 7.9870 & 7.9888 & $*$ & 7.9888 & & & & \\
\hline $4_{b}$ & 7.9853 & 7.9870 & 7.9888 & $*$ & & & & \\
\hline $5_{b}$ & & & & & $*$ & 7.9888 & 7.9870 & 7.9853 \\
\hline $6_{b}$ & & & & & 7.9888 & $*$ & 7.9888 & 7.9870 \\
\hline $7_{b}$ & & & & & 7.9870 & 7.9888 & * & 7.9888 \\
\hline $8_{b}$ & & & & & 7.9853 & 7.9870 & 7.9888 & $*$ \\
\hline \multicolumn{9}{|c|}{ Inter-Tour Prices } \\
\hline $1_{b}$ & & & & & 7.9865 & 7.9856 & 7.9846 & 7.9837 \\
\hline $2_{b}$ & & & & & 7.9856 & 7.9846 & 7.9837 & 7.9827 \\
\hline $3_{b}$ & & & & & 7.9846 & 7.9837 & 7.9827 & 7.9818 \\
\hline $4_{b}$ & & & & & 7.9837 & 7.9827 & 7.9818 & 7.9809 \\
\hline $5_{b}$ & 7.9865 & 7.9856 & 7.9846 & 7.9837 & & & & \\
\hline $6_{b}$ & 7.9856 & 7.9846 & 7.9837 & 7.9827 & & & & \\
\hline $7_{b}$ & 7.9846 & 7.9837 & 7.9827 & 7.9818 & & & & \\
\hline $8 b$ & 7.9837 & 7.9827 & 7.9818 & 7.9809 & & & & \\
\hline \multicolumn{9}{|c|}{ Stage 3: Legacy Carriers Prices } \\
\hline $1_{b}$ & $*$ & 7.9830 & 7.9830 & 7.9830 & 7.9830 & 7.9830 & 7.9830 & $7 . .8930$ \\
\hline $2_{b}$ & 7.9830 & $*$ & 7.9830 & 7.9830 & 7.9830 & 7.9830 & 7.9830 & 7.9830 \\
\hline $3_{b}$ & 7.9830 & 7.9830 & $*$ & 7.9830 & 7.9830 & 7.9830 & 7.9830 & 7.9830 \\
\hline $4_{b}$ & 7.9830 & 7.9830 & 7.9830 & $*$ & 7.9830 & 7.9830 & 7.9830 & 7.9830 \\
\hline $5_{b}$ & 7.9830 & 7.9830 & 7.9830 & 7.9830 & $*$ & 7.9830 & 7.9830 & $7 . .9830$ \\
\hline $6_{b}$ & 7.9830 & 7.9830 & 7.9830 & 7.9830 & 7.9830 & $*$ & 7.9830 & 7.9830 \\
\hline $7_{b}$ & 7.9830 & 7.9830 & 7.9830 & 7.9830 & 7.9830 & 7.9830 & $*$ & $7 . .9830$ \\
\hline $8 b$ & 7.9830 & 7.9830 & 7.9830 & 7.9830 & 7.9830 & 7.9830 & 7.9830 & $*$ \\
\hline \multicolumn{9}{|c|}{ Stage 4: Legacy Carriers Prices } \\
\hline $1_{b}$ & $*$ & 7.9821 & 7.9821 & 7.9821 & 7.9821 & 7.9821 & 7.9821 & 7.9821 \\
\hline $2_{b}$ & 7.9821 & $*$ & 7.9821 & 7.9821 & 7.9821 & 7.9821 & 7.9821 & 7.9821 \\
\hline $3_{b}$ & 7.9821 & 7.9821 & * & 7.9821 & 7.9821 & 7.9821 & 7.9821 & 7.9821 \\
\hline $4_{b}$ & 7.9821 & 7.9821 & 7.9821 & * & 7.9821 & 7.9821 & 7.9821 & 7.9821 \\
\hline $5_{b}$ & 7.9821 & 7.9821 & 7.9821 & 7.9821 & $*$ & 7.9821 & 7.9821 & 7.9821 \\
\hline $6_{b}$ & 7.9821 & 7.9821 & 7.9821 & 7.9821 & 7.9821 & $*$ & 7.9821 & 7.9821 \\
\hline $7_{b}$ & 7.9821 & 7.9821 & 7.9821 & 7.9821 & 7.9821 & 7.9821 & $*$ & 7.9821 \\
\hline $8_{b}$ & 7.9821 & 7.9821 & 7.9821 & 7.9821 & 7.9821 & 7.9821 & 7.9821 & $*$ \\
\hline
\end{tabular}


On the other hand, travel time in the entrants' sub-tour network between non-adjacent cities is longer than in the HS network. Entrants therefore charge lower prices than legacy carriers for these routes $^{18}$. In this simulation, all non-adjacent routes have lower prices; if we allow for differences in cost per seat mile parameters, so that the entrants are a priori low cost, it may well be that all routes will have lower prices.

The result that entrants' prices are for the most part lower is strengthened if instead of operating from/to primary airports (shared with legacy carriers) the entrants instead operate from 'secondary' airports such as Providence near Boston and Long Island near New York City. Entrants' passengers incur a loss in utility from traveling to secondary airports for which they are compensated by lower prices. That entrants' may charge lower prices due to increased passenger inconvenience is an important component in any analysis of the impact on social welfare.

A comparison of stage 1 and 3 prices shows that entry results in legacy carriers' charging lower prices. This is because the loss of demand results in an optimal reduction of flight frequencies. Now suppose the entrants' exit the intra-group $B$ market- with demand bouncing back, legacy carriers will increase flight frequencies and therefore prices. To an outside observer this may appear to be predatory pricing when in fact this is the result of optimal network design. As such, our explanation offers a new perspective on incumbent's pricing in response to entry and exit (Bamberger and Carlton (2006), Eckert and West (2006), Edlin (2001), Edlin and Farrell (2004), Ito and Lee (2004)).

In stage 4 , when legacy carriers adjust network structure, aircrafts, fleet, prices and flight frequencies, legacy prices for intra-group $B$ and all inter-group travel decline even further.

\subsubsection{The Impact of Entry on Costs, Profits and Social Welfare}

Table 7 summarizes costs, revenue, profits and social welfare in the four stage game. In every stage, legacy carriers have lower variable cost per seat-mile in group $B$ than group $A$ owing to the larger aircrafts in group $B$. As legacy aircrafts are fixed in stages 1 and 3, entrants' have no impact on $V C(k)$; in stage 4 however as legacy carriers respond with larger aircrafts, the $V C(k)$ is lower than stages 1 and 3, which may be and has been interpreted as competition's salubrious impact on legacy carriers competitive position. In fact, competition is not rendering legacy carriers more efficient; rather their lower costs is due an optimal response in network design.

Comparing legacy carriers' variable cost per seat mile in group $B$ with LCCs in stage 2 shows what economists have long argued: HS networks are generally more efficient than non-HS networks. This is in contrast to the business literature in which 'low fare carriers' such as Southwest are axiomatically 'low cost carriers'. Ceteris paribus, operating smaller aircrafts leads to higher cost per seat mile ${ }^{19}$. There is some evidence to support our claim that LCCs are not a priori low cost. A majority of Southwest's fleet consists of the Boeing 737-300: Table 6 contains the cost per available seat mile (CASM) for the Boeing 737-300 for Southwest, US Air and American West. A breakdown of the CASM by component shows that Southwest's low cost stems from low fuel and other expenses. In fact, a comparison of crew expenses across all aircrafts (not shown in Table 6) indicates that US Air has lower crew costs. Southwest's lower fuel costs clearly stems from its well known fuel hedging strategy executed by its management team. In this sense, legacy carriers can be blamed for being inefficient where the finger may be pointed at management instead of network structure and design. While entrants have a higher variable cost per seat mile their total variable cost is lower than legacy carriers. This is because $T V C$ is the total seat miles times variable cost per seat mile $T V C(k)=S M(k) V C(k)$. Entrants' higher $V C(k)$ is countered by their lower $S M(k)$ which raises the question of whether entrants operating smaller aircrafts than legacy carriers will

\footnotetext{
${ }^{18}$ Ceteris paribus for intra-group intra-tour travel between cities $i, j$ the HS network has lower prices if the distance in the HS itinerary is shorter than a $k>1$ network itinerary: $2 R<2 \pi R|i-j| / n \rightarrow|i-j|>n / \pi$.

${ }^{19}$ This raises the question of when an entrant will be a 'low cost carrier'. Without imposing severe restrictionssuch as on flight frequencies-it is very difficult to provide answers. For example, if we allow differences in $\alpha, \beta$, it will lead to changes in flight frequencies, which leads to a change in aircraft size. A priori, it is difficult to predict what will happen and leave this question to be investigated in further research.
} 
Table 6: Boeing 737-300: CASM Comparison

\begin{tabular}{lccccc}
\hline \hline & Crew & Fuel & Maintenance & Other & CASM \\
\hline \hline US Air & 1.2 & 3.7 & 1.1 & 0.2 & 7.3 \\
AWA & 1.0 & 3.1 & 1.8 & 0.1 & 7.2 \\
Southwest & 1.1 & 1.7 & 0.8 & 0.0 & 4.3 \\
\hline \hline
\end{tabular}

Source: CreditSights. All figures in cents. Some categories omitted.

Table 7: Cost, Revenue, Profits and Social Welfare in the Four-Stage Game

\begin{tabular}{lccccccc}
\hline \hline Stage: & \multicolumn{2}{c}{ Stage 1 } & Stage 2 & \multicolumn{2}{c}{ Stage 3 } & \multicolumn{2}{c}{ Stage 4} \\
Carrier: & \multicolumn{2}{c}{ Legacy } & Entrant & \multicolumn{2}{c}{ Legacy: Short run } & \multicolumn{2}{c}{ Legacy: Long Run } \\
Group: & $A$ & $B$ & $B$ & $A$ & $B$ & $A$ & $B$ \\
\hline \hline$f(k)($ daily $)$ & 0.40 & 0.21 & 0.19 & 0.40 & 0.13 & 0.40 & 0.13 \\
$S(k)($ seats) & 911 & 1796 & 208 & 911 & 1738 & 911 & 2444 \\
\hline \hline$V C(k)(\$ /$ seat-mile) & 2.384 & 2.194 & 3.681 & 2.384 & 2.194 & 2.384 & 2.143 \\
$T V C(k)(\$ \mathrm{~m})$ & 0.013 & 0.082 & 0.011 & 0.013 & 0.073 & $0 . .013$ & 0.065 \\
$T F C(k)(\$ \mathrm{~m})$ & 0.023 & 0.099 & 0.022 & 0.023 & 0.081 & 0.023 & 0.081 \\
Passenger Cost $(\$ \mathrm{~m})$ & 0.019 & 0.008 & & 0.012 & 0.015 \\
Airline Cost $(\$ \mathrm{~m})$ & 0.218 & 0.022 & & 0.191 & 0.184 \\
$R(k)(\$ \mathrm{~m})$ & 8.065 & 2.235 & & 5.826 & & 5.825 \\
$C(k)(\$ \mathrm{~m})$ & 0.237 & 0.031 & & 0.204 & & 0.200 \\
$\Pi(k)(\$ \mathrm{~m})$ & 7.827 & 2.204 & 5.621 & 5.625 \\
\hline \hline Social Welfare $(\$ \mathrm{~m})$ & 7.833 & \multicolumn{7}{c}{7.825} & 7.829 \\
\hline \hline
\end{tabular}

always have lower $T V C(k)$ ? Denoting entrants with $E$ and legacy carriers by $L$, the entrants total seat miles is smaller than legacy carriers if $S M\left(k_{E}=4\right)<S M\left(k_{L}=1\right)$ :

$$
2\left\{2 \pi R_{b}\left(k_{E}-1\right) / n_{b}+R_{b}\right\}\left\{\left(n_{b}-k_{E}\right) d_{b b}\right\} n_{b}<2\left\{2 \pi R_{b}\left(k_{L}-1\right) / n_{b}+R_{b}\right\}\left\{\left(n_{b}-k_{L}\right) d_{b b}+n_{a} d_{b a}\right\} n_{b}
$$

If $k_{E}>k_{L}$ - entrants operates a sub-tour network and legacy carriers operate HS network- this inequality holds if:

$$
\begin{aligned}
\left(n_{b}-k_{E}\right) d_{b b} & <\left(n_{b}-k_{L}\right) d_{b b}+n_{a} d_{b a} \\
\left(k_{L}-k_{E}\right) d_{b b} & <n_{a} d_{b a}
\end{aligned}
$$

which implies that as long as legacy carriers have some inter group demand, entrants will have lower $T V C(k)$ so long as they operate with smaller aircraft and a network with sub-tour length greater than legacy carriers. Thus, given legacy carriers' HS network, entrants could only have had lower total cost by operating sub-tour $k>1$ networks which is exactly what is observed.

We digress to compare P2P and HS networks. Suppose entrants operate smaller aircraft than legacy carriers. Then $T V C(k=0)<T V C(k=1)$ so long as:

$$
\begin{aligned}
2\left\{2 \pi R_{b}(-1) / n_{b}+R_{b}\right\}\left\{\left(n_{b}\right) d_{b b}\right\} n_{b} & <2\left\{R_{b}\right\}\left\{\left(n_{b}-1\right) d_{b b}+n_{a} d_{b a}\right\} n_{b} \\
\left\{R_{b}-2 \pi R_{b} / n_{b}\right\}\left\{\left(n_{b}\right) d_{b b}\right\} & <\left\{R_{b}\right\}\left\{\left(n_{b}-1\right) d_{b b}+n_{a} d_{b a}\right\}
\end{aligned}
$$

Since $\left\{R_{b}-2 \pi R_{b} / n_{b}\right\}<R_{b}$ this implies that $n_{b} d_{b b}$ cannot be too large compared to $\left\{\left(n_{b}-1\right) d_{b b}+\right.$ $\left.n_{a} d_{b a}\right\}$. 
Since all carriers are assumed to practice yield management, there is no consumer surplus in this model so that social welfare is the sum of legacy and entrants carriers' profits. From Table 7, comparing stages 1 and 3, we note that it is possible for social welfare to be lower due to entry by non-HS network carriers. This is despite the fact entrants charge lower prices and operate flights with higher frequency- the source of the social welfare loss is some entrants' passengers being inconvenienced from longer travel times in a sub-tour network and from the legacy carriers lower flight frequencies which inconveniences their passengers. When combined with lower legacy profits it is possible for social welfare to be lower.

It may appear that this result is conditional on zero consumer surplus- however, if we allow for positive consumer surplus it offsets carriers profits by the same amount so that social welfare will not change. This result, though theoretical, suggests that competition by LCCs, made possible under deregulation may not have necessarily lowered social welfare. This suggests that social welfare may well have been higher if entry by non-HS carriers had been restricted. This of course would have meant that policy-makers had anticipated HS networks to be optimal for the U.S. airline industry and accordingly encouraged competition by HS carriers but not non-HS carriers. In contrast, in the EU, the optimal network may well be P2P or subtour networks, so that entry by HS networks should be discouraged there.

\section{Conclusion}

We extended LNs model and applied it to the evolution of the U.S. airline industry following deregulation in 1978. We show that under certain conditions on the models parameters, which we argue are aligned with the data, it was optimal for incumbent carriers to form HS network structures. With a different set of parameters (e.g. the short distances of Europe, especially in an era of dominating flag carriers), HS might not be optimal. We further show that for entrants facing established HS networks, it is optimal to form non-HS networks. Moreover, the effect of entrants on incumbents pricing is the optimal network design response. Entrants need not charge lower prices across the spectrum, especially when the disutility of entrants service to the consumer, or passenger inconvenience, due to longer travel times is small enough. Finally, we show that because of passenger inconvenience, under certain conditions on parameters the impact of free entry (new entrants cherry picking, i.e. offering P2P service between two non-hub cities) on social welfare is negative, suggesting entries to be regulated in the industry.

It may appear that our suggestion to restrict entry by non-HS network carriers may be wishful thinking in hindsight. However, we feel that this policy has applications for the future. Consider the optimal network structure and design of LCCs as these expand, or are forced to expand, due to pressures from Wall Street. With a greater number of cities, expanding distances, and lower demand routes, the analysis of stage 1 indicates that the LCCs will have to shift from sub-tour to HS networks. In fact, the measure of network structure $b$ in Table 2 shows that this precisely what's happening. Southwest and JetBlue in 2006 are operating non-P2P networks and it is our guess that they will increasingly do so. Under deregulation, this raises the spectre of history repeating itself: with barriers to entry, social welfare, and, Southwest and JetBlue's profitability, may well be undermined by another wave of non-HS network carriers. Therefore, we advocate a closer look at this possibility and suggest, if warranted, re-regulating the industry to allow entry by HS carriers only. 


\section{REFERENCES}

Abramowitz, A. D. and Brown, S. M. (1990). The Effects of Hub Dominance and Barriers to Entry on Airline Competition and Fares. Mimeo. U.S. General Accounting Office, Washington D.C.

Adler, N. (2005). Hub-Spoke Network Choice Under Competition with an Application to Western Europe. Transportation Science, 39:1, 58-72

Bamberger, G.E. and Carlton, D.W. (2006). Predation and the Entry and Exit of Low-Fare Carriers, in, Lee, D. (ed), Advances in Airline Economics 1: Competition Policy and Antitrust. Elsevier.

Banerjee, A. and Summers, L. (1987). On Frequent-Flyer Programs and Other Loyalty-Inducing Economics Arrangements. Harvard Institute of Economic Research, Discussion Paper \#1332.

Barla, P. (1999). Demand Uncertainty and Airline Network Morphology with Strategic Interaction. Universite Laval

Berechman, J. and Shy, O. (1996). The Structure of Airline Equilibrium Networks, in, Recent Advances in Spatial Equilibrium Modeling, edited van de Bergh, J.C.J.M, Nijkamp, P. and Rietveld, P., Springer Press.

Berechman, J. and Shy, O. (1998). Network Structure and Entry in the Deregulated Airline Industry. Keio Economic Studies, 35:71-82.

Berry, T., Moreno-Hines, F., Wells, M., Bhadra, D., Nelson, G. (2004). Airline Network Characteristics and Connectivity. Space Policy Institute, George Washington University.

Berry, S., Carnall, M., Spiller, P. T. (2006). Airline Hubs: Costs, Markups and the Implications of Customer Heterogeneity in Advances in Airline Economics: Competition Policy and Antitrust, Volume 1 edited Darrin Lee. Elsevier.

Bittlingmayer, G. (1990). Efficiency and Entry in a Simple Airline Network. International Journal of Industrial Organization 8:245-257.

Borenstein, S. (1989). Hubs and high fares: dominance and market power in the US airline industry. Rand Journal of Economics, 20, 344-365.

Borenstein, S. (1992). The Evolution of Airline Competition. Journal of Economic Perspectives, 6, 45-73

Brueckner, J.K. (2004). Network Structure and Airline Scheduling. The Journal of Industrial Economics, Volume LII, 291-312

Brueckner, J. and Spiller, P.T. (1994). Economies of Traffic Density in the Deregulated Airline Industry. Journal of Law and Economics, 35, 379-415

Brueckner, J.K., Goebel, A., and Niskanen, E. (1997). Airline Deregulation: The American Experience and Prospects for Europe. Vatt-Keskustelualoitteita, Helsinki

Caves, D. W., Christensen, L.R., Tretheway, M.W. (1984). 'Economies of Density Versus Economies of Scale: Why Trunk and Local Service Airline Costs Differ'. Rand Journal of Economics, 15:471-89

Daniels, J. I. (1995). Congestion Pricing and Capacity of Large Hub Airports: a Bottleneck Model with Stochastic Queues. Econometrica, 63:2, 327-370.

Daniel, J. and Pahwa, M. (2007). There and Back Again: Airline Routes, Fares, and Passenger Flows in Network Equilibria. Working Paper, Department of Economics, Alfred Lerner College of Business and Economics, University of Delaware 
Dhebhar, A. (1993). American Airlines, Inc.: Revenue Management. HBS Case 9-190-029

Doganis, R. (1993). Flying Off Course: The Economics of International Airlines. Routledge. London, UK.

Eckert, A. and West, D.S. (2006). Predation in Airline Markets: A Review of Recent Cases, in, Lee, D. (ed), Advances in Airline Economics 1: Competition Policy and Antitrust. Elsevier.

Edlin. A.S. (2001). Stopping Above-Cost Predatory Pricing. Yale Law Journal, 111:941-991

Edlin, A.S. and Farrell, J. (2004). The American Airlines Case: A Chance to Clarify Predation Policy, in, The Antitrust Revolution: Economics, Competition, and Policy, Kwoka, J., and White, L. (eds).

Evans, W., and I. Kessides (1993). Localized Market Power in the U.S. Airline Industry. Review of Economics and Statistics, 75, 66?75

Hendricks, K., Piccione, M. and Tan, G. (1995). The Economics of Hubs. The Review of Economic Studies, 62:1, 83-99

Hendricks, K., Piccione, M. and Tan, G. (1999). Equilibria in Networks. Econometrica, 67:6, 1407-1434

Heskett, J. (2003). Southwest Airlines 2002: An Industry Under Siege. HBS Case 9-803-133

Hussain, S. A. (2006). Airline Network Design and Profitability: a Case for Re-Regulation? Proceedings of the 6th GCBE Conference. Cambridge, MA.

Ito, H. and Lee, D. (2004). Incumbent Response to Lower Cost Entry: Evidence from the U.S. Airline Industry. Unpublished paper.

Lederer, P. and Nambimadom, R.S. (1998). Airline Network Design. Operations Research, 46:6, 785-804

Lee, D. (ed.) (2006). Advances in Airline Economics: Competition Policy and Antitrust, Volume 1. Elsevier.

Lee, D. and Luengo-Prado, M. (2005). The Impact of Passenger Mix on Reported Hub Premiums in the U.S. Airline Industry. Southern Economic Journal. 72:2, 372-394

Mayer, C., Sinai, T. (2002). Network Effects, Congestion Externalities, and Air Traffic Delays: or why Delays are not Evil. NBER Working Paper 8701.

McCraw, T. (1984). Prophets of Deregulation. Harvard University Press, Cambridge, MA

Meyer, J.R., Oster Jr., C.V, and Morgan, I.P., Berman, B.A., Strassmann, D.L., (1981). Airline Deregulation: The Early Experience. Auburn House Publishing Company, Boston, MA.

McGahan, A. (1995). The U.S. Airline Industry in 1995. HBS Case 9-795-113. Harvard Business School, Boston, MA.

Morrison, S. A. and Winston, C. (1990). The Dynamics of Airline Pricing and Competition. The American Economic Review, 80:2, 389-393

Morrison, S. A. and Winston, C. (1995). The Evolution of the Airline Industry. The Brookings Institution.

Oum, T.H, Zhang, A., and Zhang, Y. (1995). Airline Network Rivalry. Canadian Journal of Economics, 95: $836-857$ 
Schipper, Y. and Nijkamp, P. (1998). Deregulation and Schedule Competition in Simple Airline Networks. Free University Amsterdam, Tinbergen Institute.

Shy, O. (2001). The Economics of Network Industries. Cambridge University Press, Cambridge, UK..

Starr, R.M, and Stinchcomebe, M.B. (1992). Efficient Transportation Routing and Natural Monopoly in the Airline Industry: An Economic Analysis of Hub-Spoke and Related Systems. Discussion Paper 92-25, Department of Economics, University of California, San Diego. 